\title{
Damage and Degradation of Concrete under Coupling Action of Freeze-Thaw Cycle and Sulfate Attack
}

\author{
Wei Tian (i) and Fangfang Gao \\ School of Civil Engineering, Chang'an University, Xi'an 710061, China \\ Correspondence should be addressed to Fangfang Gao; 429757009@qq.com
}

Received 30 August 2019; Revised 23 December 2019; Accepted 13 January 2020; Published 14 February 2020

Academic Editor: Zbyšek Pavlík

Copyright ( ) 2020 Wei Tian and Fangfang Gao. This is an open access article distributed under the Creative Commons Attribution License, which permits unrestricted use, distribution, and reproduction in any medium, provided the original work is properly cited.

\begin{abstract}
In this study, the mechanical behaviors, failure characteristics, and microstructure of concrete containing fly ash (FA) against combined freeze-thaw cycles and sulfate attack were studied compared with normal concrete, and the formation rates of corrosion products during coupling cycles were investigated. Results showed that, during the coupling action of freeze-thaw cycles and sodium sulfate solution, concrete containing $10 \%$ fly ash exposed in 5\% sodium sulfate solution exhibited better freeze-thaw resistance. Meanwhile, the variation of compressive strength of concrete during the coupling cycles could be divided into two stages, including the strength enhancement stage and the strength reduction stage. Moreover, the proportion of micropores and capillary pores decreased obviously during combined freeze-thaw cycles and sulfate attack, and excessive concentration of sodium sulfate solution led to more macropores after high-frequency freeze-thaw cycles.
\end{abstract}

\section{Introduction}

There are numerous factors that affect the durability and service life of concrete, such as carbonation, sulfate corrosion, alkali polymerization expansion, cold and hot cycle, freezethaw cycle, dry-wet cycle, and reinforcement corrosion [1-3]. Among them, in the extreme environment such as saline soil, the deterioration of the structure and the reduction of durability and service life of cement-based materials are mainly caused by external sulfate erosion and freeze-thaw action [4-6]. Freeze-thaw cycle leads to the decline of durability of concrete and finally leads to the formation and development of cracks $[4,5]$. Dissolved sulfates react with cement-based materials, causing concrete to expand, crack, peel, and disintegrate $[6,7]$. Sulfate attack of concrete under the freezethaw cycle is a very convoluted process, including physical effects caused by salt crystallization and chemical reaction between ions [8-11]. Therefore, it is of great significance to study the performance of concrete under the coupling action of the freeze-thaw cycle and sulfate attack.

Numerous works of deterioration of macroscopic properties of concrete exposed to freeze-thaw cycles in salt solution have been reported. Li et al. [12] studied the durability of recycled concrete with fly ash exposed to 5\% sodium sulfate solution under freeze-thaw cycles. They argued that the positive effect of sulfate attack on the freezethaw cycle is greater than the negative effect. Wang et al. [13] evaluated durability of concrete containing fly ash $(10 \%$, $15 \%$, and $25 \%$ by weight) against combined freeze-thaw cycle and sulfate attack, and they concluded that concrete with $25 \%$ fly ash has the best freeze-thaw resistance in $10 \%$ sodium sulfate solution. Maes and De Belie [14] pointed out that the presence of the chloride ion can alleviate sulfate attack, and the permeability of the chloride ion increases with the increase of salt concentration. Jiang et al. [15] examined the freeze-thaw cycle performance of $20 \%$ fly ash concrete exposed to $5 \%$ sodium sulfate solution and revealed the interaction between freeze-thaw cycle and sulfate attack. Sulfate corrosion speeds up the formation of microcracks in concrete and causes more serious damage during freezethaw cycles. Also, the lower the freeze-thaw cycle temperature, the slower the diffusion rate of sulfate ions in concrete. Wang and Niu [16] investigated the freeze-thaw and sulfate resistance of shotcrete. They concluded that shotcrete is 
more durable than ordinary concrete under freeze-thaw cycles and sulfate ion erosion, and steel fiber made a considerably dense microstructure in concrete, which could significantly improve the compressive strength. Zhang et al. [17] considered the freeze-thaw resistance of concrete under the action of magnesium sulfate. Their experimental results indicated that the lowering freezing point of magnesium sulfate solution could substantially reduce the freeze-thaw damage of concrete.

These studies mainly focus on the macroperformance of concrete in sulfate solution subjected to freeze-thaw cycles. However, the change of macroperformance is essentially brought about by the change of the microstructure [18]. The study of durability of concrete from the aspect of microperformance is limited. Yang et al. [19] studied the effects of sulfate attack and freeze-thaw alternation on the microstructure of concrete by water absorption, X-ray diffraction, and scanning electron microscopy. They reported that, under the coupling action of sulfate corrosion and freezethaw cycle, freeze-thaw damage is the main factor of concrete damage. Tian and Han [20] investigated the porosity and pore distribution of concrete exposed to freeze-thaw cycles by CT technique and suggested that freeze-thaw cycles accelerate the mesodamage in concrete, and the fractal dimension of the pore structure increases first and then decreases during freeze-thaw cycles.

Fly ash and sulfate solution have both positive and negative effect on the resistance of concrete subjected to freeze-thaw cycle. Though concrete suffered from sulfate attack, it drops the freezing point of the pore solution [21]. Adding fly ash into concrete could optimize the microstructure to a certain extent $[22,23]$; according to Yazic1 [24], FA has a positive effect on the mechanical properties, freeze-thaw properties, and chloride penetration resistance of concrete, whereas Li et al. [12] argued that cement-based materials mixed with high-content FA produce adverse effects on compressive strength. In fact, it is not clear how much the dosage of fly ash and sodium sulfate solution is beneficial for improving deterioration resistance of concrete exposed to combined freeze-thaw cycles and sulfate attack. In this paper, the performance of concrete with different contents of fly ash under the coupling action of freeze-thaw cycle and sulfate attack in separate concentration of sodium sulfate solution is studied in detail from the microlevel. Furthermore, the appropriate dose of fly ash and sodium sulfate solution under the combined action of freeze-thaw cycles and sulfate attack was also analyzed.

\section{Materials and Methods}

2.1. Materials. Ordinary Portland cement (OPC) of 42.5 was used as the cementitious material. The continuous grading coarse aggregate ranges from $5 \mathrm{~mm}$ to $30 \mathrm{~mm}$. And the fine aggregate used in this work was natural river sand with fineness modulus of 3.4. Second-grade fly ash was used in this study. All of these raw materials were chosen in accordance with Chinese standards and requirements of extreme environment. The air content of concrete was $1.8 \%$, and the $\mathrm{C}_{3} \mathrm{~A}$ content of cement was $7.02 \%$. W/C ratio of 0.4 was adopted for each case, and to improve the workability of concrete, naphthalene superplasticizer with different dosages by the cement weight was used in this work to keep the slump in the range of $50-120 \mathrm{~mm}$. Tap water was used for mixing concrete. And their properties are listed in Tables 1 and 2.

2.2. Mix Proportion and Specimen Preparation. The optimum mix ratio was determined by the experiment, and the actual mix proportion of specimens investigated in this work is shown in Table 3. For the preparation of fly ash concrete, ordinary Portland cement and aggregate were mixed using a single horizontal-axis forced mixer. The concrete mixtures were poured into $100 \mathrm{~mm}$ cube moulds and then demolded after $24 \mathrm{~h}$ and stored in wet environment $\left(20 \pm 2^{\circ} \mathrm{C}\right.$ and $95 \%$ relative humidity) for $24 \mathrm{~d}$. Subsequently, the specimens were immersed in water for $4 \mathrm{~d}$. And the rapid freeze-thaw test was conducted on $28 \mathrm{~d}$-old specimens in accordance with GB/T50082-2009 [25].

To investigate the corrosion damage of fly ash concrete during freeze-thaw cycles, three groups of sodium sulfate concentration $(2 \%, 5 \%$, and $10 \%)$ were prepared to stimulate the actual environment. For each group, concrete mixtures with three different FA contents (i.e., $0 \% 10 \%$, and $20 \%$ ) as partial replacement of cement and all specimens were immersed in the corresponding sodium sulfate solution and placed in a freeze-thaw test machine to conduct the quick freeze-thaw cycle test. The freeze-thaw cycle was $0,50,100$, 150, and 200 times. During each freeze-thaw cycle, the specimens were cooled from $20 \pm 2^{\circ} \mathrm{C}$ to $-20 \pm 2^{\circ} \mathrm{C}$ within $2 \mathrm{~h}$ and warmed from $-20 \pm 2^{\circ} \mathrm{C}$ to $20 \pm 2^{\circ} \mathrm{C}$ within $1 \mathrm{~h}$. And the run time per cycle lasts for a total of 3hours, which is a reasonable range according to the test code for hydraulic concrete (SL352-2006) of China (see Figure 1). The minimum freezing temperature at the center of the specimen is $-22^{\circ} \mathrm{C}$. Repeat the cycle according to the set number of freeze-thaw cycles and terminate when the following exceptional conditions occur: (a) the mass loss rate of the specimens exceed 5\%; (b) the relative dynamic elastic modulus decreased by $60 \%$ compared with non-freeze-thaw cycle. A total of 135 specimens were prepared in the lab for the experiments. For each case, three specimens were tested according to GB/T50081-2002 [26], and the average value of three specimens under the same conditions was given. The specimen groups are given in Table 4.

\subsection{Methods}

2.3.1. Freeze-Thaw Cycles and Sulfate Corrosion. To evaluate durability of freeze-thaw and sulfate resistance of concrete with and without fly ash, $100 \mathrm{~mm}$ cubic specimens cured for 28 days were immersed in specified solution (i.e., $2 \%, 5 \%$, and $10 \%$ sodium sulfate by wt. $\%$ ) for rapid freeze-thaw test. According to the Chinese standard GB/T50082-2009, the standard freeze-thaw cycle time was set to $3 \mathrm{~h}$, and the specific process is as follows: firstly, three concrete specimens in the same group were put into the test barrel, and then $0.8 \mathrm{~L} \mathrm{~N} \quad \mathrm{Na}_{2} \mathrm{SO}_{4}$ solution with the corresponding 
TABle 1: Properties and chemical composition of ordinary Portland cement.

\begin{tabular}{|c|c|c|c|c|c|c|c|c|c|c|c|c|c|c|c|}
\hline \multirow{2}{*}{$\begin{array}{l}\mathrm{MgO} \\
(\%)\end{array}$} & \multirow{2}{*}{$\begin{array}{c}\mathrm{Al}_{2} \mathrm{O}_{3} \\
(\%)\end{array}$} & \multirow{2}{*}{$\begin{array}{l}\mathrm{CaO} \\
(\%)\end{array}$} & \multirow{2}{*}{$\begin{array}{c}\mathrm{Fe}_{2} \mathrm{O}_{3} \\
(\%)\end{array}$} & \multirow{2}{*}{$\mathrm{SiO}_{2}$} & \multirow{2}{*}{$\begin{array}{l}\mathrm{SO}_{3} \\
(\%)\end{array}$} & \multirow{2}{*}{$\begin{array}{c}\text { Loss on } \\
\text { ignition } \\
\text { (\%) }\end{array}$} & \multirow{2}{*}{$\begin{array}{l}\mathrm{Cl}^{-1} \\
(\%)\end{array}$} & \multirow{2}{*}{$\begin{array}{c}\text { Surface } \\
\text { area }\left(\mathrm{m}^{2}\right)\end{array}$} & \multirow{2}{*}{$\begin{array}{c}\text { Fineness } \\
(\%)\end{array}$} & \multicolumn{2}{|c|}{$\begin{array}{c}\text { Setting } \\
\text { time (min) }\end{array}$} & \multicolumn{2}{|c|}{$\begin{array}{c}\text { Flexural } \\
\text { strength } \\
(\mathrm{MPa})\end{array}$} & \multicolumn{2}{|c|}{$\begin{array}{l}\text { Compressive } \\
\text { strength } \\
\text { (MPa) }\end{array}$} \\
\hline & & & & & & & & & & $\begin{array}{c}\text { Initial } \\
\text { setting time }\end{array}$ & $\begin{array}{c}\text { Final setting } \\
\text { time }\end{array}$ & $3 \mathrm{~d}$ & $28 \mathrm{~d}$ & $3 \mathrm{~d}$ & $28 \mathrm{~d}$ \\
\hline 1.06 & 5.13 & 64.37 & 5.25 & 21.66 & 2.03 & 1.19 & $\leq 0.06$ & 300 & 3.8 & $\geq 45$ & $\leq 180$ & 4.5 & 7.0 & 18.0 & 36.0 \\
\hline
\end{tabular}

Table 2: Properties and chemical composition of fly ash.

\begin{tabular}{lccccc}
\hline Fineness $(\mu \mathrm{m})$ & Density $\left(\mathrm{g} / \mathrm{cm}^{3}\right)$ & Specific surface area $\left(\mathrm{m}^{2} / \mathrm{kg}\right)$ & Loss & $\mathrm{SO}_{3}(\%)$ & $\mathrm{CaO}(\%)$ \\
\hline 43 & 2.12 & 360 & 2.34 & 2.14 & 16 \\
\hline
\end{tabular}

TABle 3: Mix proportions in $\mathrm{kg} / \mathrm{m}^{3}$ (except $\mathrm{w} / \mathrm{c}$ ) of concretes investigated in this study.

\begin{tabular}{lcccccc}
\hline \multirow{2}{*}{ Cement } & \multicolumn{2}{c}{ Fly ash } & Coarse aggregates & Fine aggregates & Water w/c = 0.4 & Superplasticizer (\%) \\
& $\%$ & $\mathrm{~kg}$ & 1211.2 & 681.3 & 145 & 1 \\
362.5 & - & - & 1211.2 & 681.3 & 145 & 0.7 \\
326.25 & 10 & 36.25 & 1211.2 & 681.3 & 145 & 0.5 \\
290 & 20 & 72.5 & & & & \\
\hline
\end{tabular}

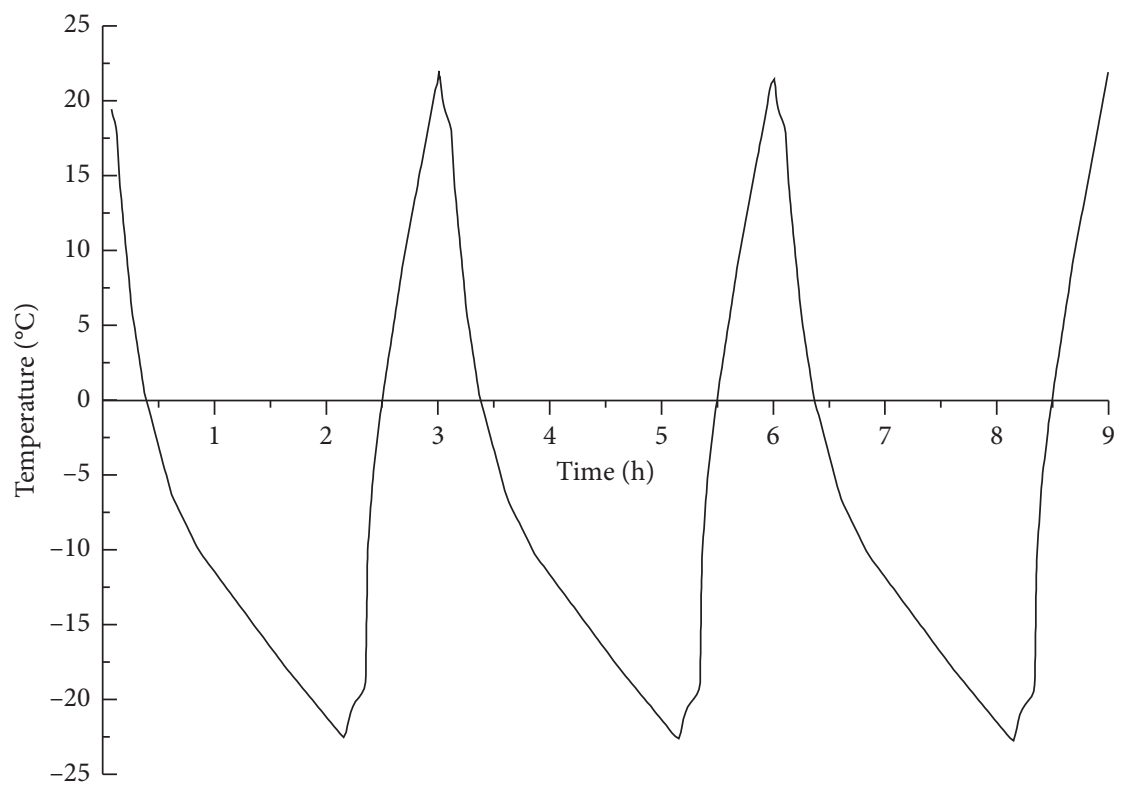

Figure 1: Temperature-time curve during the freeze-thaw cycle.

TABLE 4: Experimental specimens.

\begin{tabular}{|c|c|c|c|c|c|c|}
\hline \multirow{2}{*}{ Sodium sulfate concentration (\%) } & \multicolumn{5}{|c|}{ Freezing-thawing cycle $(n)$} & \multirow{2}{*}{ Fly ash $(\%)$} \\
\hline & 0 & 50 & 100 & 150 & 200 & \\
\hline \multirow{2}{*}{2} & A & A1 & A2 & A3 & A4 & 10 \\
\hline & $\mathrm{B} 1$ & $\mathrm{~B} 11$ & $\mathrm{~B} 21$ & B31 & B41 & 0 \\
\hline \multirow{2}{*}{5} & $\mathrm{~B} 2$ & B12 & $\mathrm{B} 22$ & B32 & B42 & 10 \\
\hline & B3 & B13 & $\mathrm{B} 23$ & B33 & B43 & 20 \\
\hline 10 & $\mathrm{C}$ & $\mathrm{C} 1$ & $\mathrm{C} 2$ & C3 & $\mathrm{C} 4$ & 10 \\
\hline
\end{tabular}

concentration was poured into the barrel; subsequently, the test barrel was located into the rapid freeze-thaw test machine (KDR-V9) for freeze-thaw test (including 50, 100, 150, and 200 cycles), and finally the macromechanical tests and microexperiments were carried out after every 50 freezethaw cycles, respectively. The mass and dynamic elastic modulus of the cubic specimens after every designated freeze-thaw cycle were measured. 
2.3.2. Compressive Strength Test. Compressive strength of specimens was tested using a YAW2000A electrohydraulic servo pressure testing machine according to the GB/T500812002. The tests were carried out in a stress-controlled mode with a loading rate of $0.5 \mathrm{MPa} / \mathrm{s}$.

2.3.3. Microstructure Characterization. In this paper, to reveal the deterioration mechanism of fly ash concrete from the micropoint of view under the coupling action of freezethaw cycle and sulfate attack, microstructure characterization of specimens was investigated by the following methods: the microcracks and corrosion products in concrete were qualitatively observed and analyzed by SEM (scanning electron microscope analysis) and EDS (energy dispersive spectroscopy); the internal components of concrete were analyzed by XRD (X-ray diffraction analysis); the pore size distribution and porosity of concrete were explored by MIP (mercury intrusion analysis); and TG-DSC (thermal analysis) was used to quantitatively analyze the corrosion products of concrete. Broken pieces were taken from compressive strength test and immersed in ethanol to prevent hydration. Before microtest, the specimens were removed from ethanol and dried at $60^{\circ} \mathrm{C}$ for $8 \mathrm{~h}$.

\section{Results and Discussion}

3.1. Macroappearance. Because all specimens completely immersed in $\mathrm{Na}_{2} \mathrm{SO}_{4}$ solution for freeze-thaw test, every side became rough due to external exfoliation and internal porosity growth under the coupling action of freeze-thaw and sulfate attack. And the surface conditions of fly ash concrete specimens after combined freeze-thaw cycles and sulfate attack are shown in Figure 2. It can be seen that, under the coupling action of freeze-thaw $(50,100,150$, and 200) and sulfate attack ( $2 \%, 5 \%$, and $10 \%)$, firstly, the surface of concrete specimens appeared shedding and pitting surface, and then with the further intensification of hydration reaction of cement slurry, aggregates gradually emerged; finally, large pieces of concrete dropped from the edges and corners of specimens and original weak place. In addition, original voids on the specimen surface enlarged, and new cracks appeared.

At the beginning of freeze-thaw cycles, 5\% sodium sulfate solution reduced erosion deterioration of concrete specimens caused by freeze-thaw cycles [12]. And at the later stage of this cycle, the higher the content of fly ash, the more serious the damage of concrete specimens. The results are in good agreement with what were suggested by Tian and Han [20] and Niuet al. [27]. Moreover, "frost" (anhydrous mirabilite) phenomenon appeared on the surface of the specimens in the later period, indicating a large number of sulfates accumulated in concrete and then would crystallize and salt out after evaporation of water.

Additionally, it was noted that concrete specimens containing $10 \%$ fly ash in $2 \% \mathrm{Na}_{2} \mathrm{SO}_{4}$ and $20 \%$ fly ash in $5 \%$ $\mathrm{Na}_{2} \mathrm{SO}_{4}$ only suffered 150 freeze-thaw cycles, compared with 200 under other conditions. This indicates that a certain concentration of $\mathrm{Na}_{2} \mathrm{SO}_{4}$ solution improved freeze-thaw
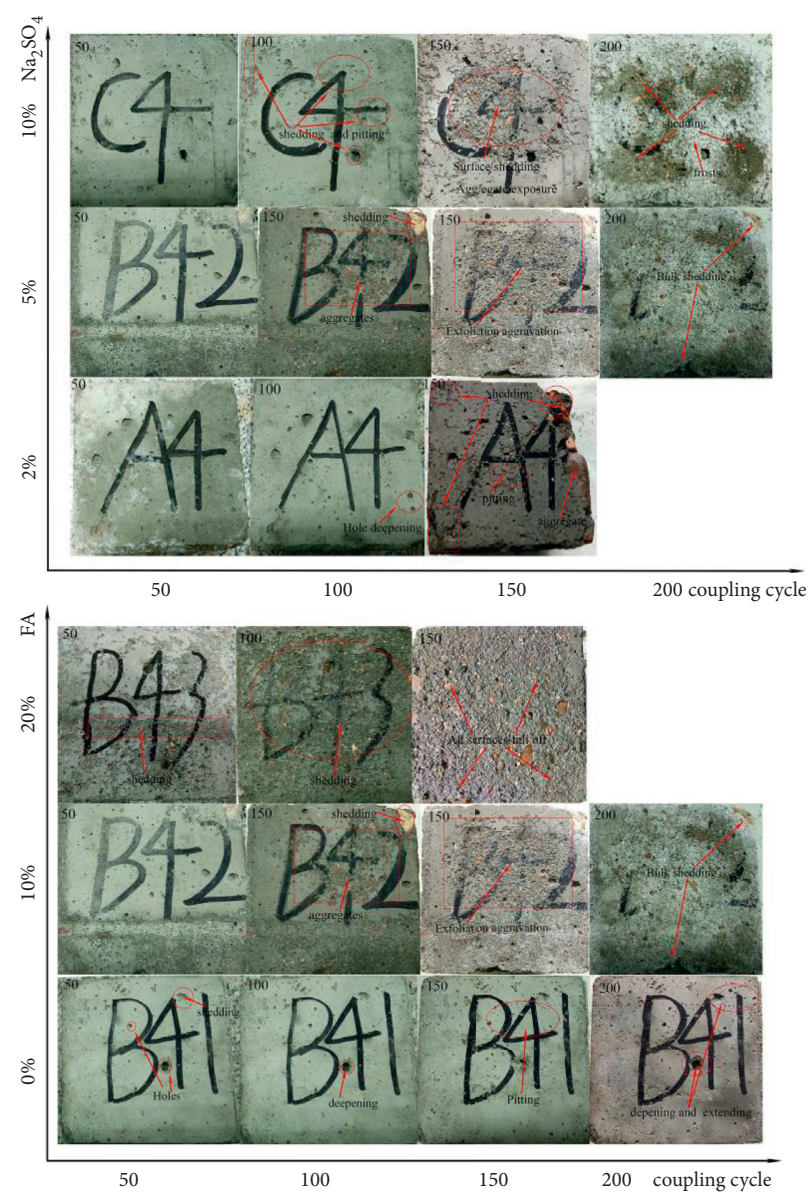

Figure 2: Morphology of fly ash concrete after coupling cycles.

resistance of concrete, but excessive fly ash content reduced this ability. Therefore, it could be concluded that $10 \%$ fly ash and $5 \% \mathrm{Na}_{2} \mathrm{SO}_{4}$ seem to be the optimum dosage for improving the freeze-thaw resistance of concrete, which is consistent with the research result of Li et al. [12], who pointed out that low content FA concrete has better antifreeze-thaw cycle performance in $5 \% \mathrm{Na}_{2} \mathrm{SO}_{4}$ solution. However, Wang et al. [13] indicated that $10 \% \mathrm{Na}_{2} \mathrm{SO}_{4}$ more obviously improve freeze-thaw resistance of concrete with $25 \%$ FA. This conclusion will be analyzed and interpreted in detail as follows.

3.2. Mass Loss. The saturated-surface dry mass was obtained after each freeze-thaw cycle, and the mass loss rate was calculated according to the following equation:

$$
M=\left(1-\frac{M_{n}}{M_{0}}\right) \times 100 \%,
$$

where $M(\%)$ is the mass loss rate after $n$ freeze-thaw cycles, $M_{0}$ is the initial mass before freeze-thaw cycles $(\mathrm{g})$, and $M_{n}$ is the mass after $n$ freeze-thaw cycles (g).

During freeze-thaw cycles, the surface of concrete is damaged (see Figure 2), which leads to decrease of specimen mass. The mass loss of the specimen under freeze-thaw cycle experienced three stages, initially decreased, then increased 
with a slow rate, and finally rapidly increased (see Figure 3(a)), which is consistent with the result of Tian and $\mathrm{Li}$ et al. [20,28]. The rate of the specimen with $20 \%$ fly ash in $5 \% \mathrm{Na}_{2} \mathrm{SO}_{4}$ before 150 freeze-thaw cycles was much higher than in other four conditions. In addition, at the later stage of freeze-thaw cycles, the increase of mass was mainly due to increasing water absorption caused by macro- and microcracks that produced from the serious deterioration of concrete.

Figure 3(b) presents the effect of fly ash content on the mass loss rate of concrete specimens. With increase of freezethaw cycles, the mass loss of the specimen increased nonlinearly, and the damage of concrete specimens with higher fly ash content deteriorated more seriously, resulting from the frost heave resistance of concrete which decreased with the increase of fly ash content. The result is contrary to what was suggested by Wang et al. [13]. Figure 3(c) shows the effect of concentration of salt solution on mass loss rate of concrete specimens. The mass loss of the specimen increased nonlinearly with the increase in number of freeze-thaw cycles, and the mass loss caused by different salt solutions was almost the same in the early stage of freeze-thaw cycles. However, after 150 freeze-thaw cycles, the mass loss rate was inversely proportional to the concentration of salt solution due to more corrosion products and crystalline salts.

3.3. Relative Dynamic Elastic Modulus (RDEM). The relative dynamic elastic modulus of the specimen after each freezethaw cycle was measured and calculated according to equation (2) to assess the internal damage of fly ash concrete caused by the couple action of freeze-thaw and sulfate attack:

$$
\Delta E_{d}=\frac{E_{d n}}{E_{d 0}} \times 100,
$$

where $\Delta E_{d}$ is the relative dynamic elastic modulus after $n$ freeze-thaw cycles, $E_{d 0}$ is the the average dynamic elastic modulus after 0 freeze-thaw cycle (MPa), and $E_{d n}$ is the average dynamic elastic modulus after $n$ freeze-thaw cycles (MPa).

Compared with mass loss rate, RDEM would be more reasonably reflected by the damage of fly ash concrete exposed to combined freeze-thaw cycles and sulfate attack. The influence of coupling action on RDEM was different from that of freeze-thaw or sulfate attack; it was more complex and changeable.

It can be seen from Figure 4 that the relative dynamic elastic modulus of concrete specimens increased in early and middle stages of freeze-thaw cycles and then decreased. High concentration of salt solution accelerated the rate of the relative dynamic elastic modulus into the decline stage. In the later stage of freeze-thaw, severe internal damage of concrete resulted in a decrease in compactness, subsequently a rapid decrease in relative dynamic modulus.

For the same concentration of salt solution (5\%), the RDEM exhibited an upward trend in the early stage of freeze-thaw cycle and then decreased rapidly (Figure 4(a)). Because of the extreme fineness of FA, the interconnecting voids between aggregate and cement can be reduced by adding FA into concrete. Besides, the pozzolanic reaction of FA improves the compactness of concrete to prevent the invasion of sulfate ions and water. The densification process of concrete under the coupling action of freeze-thaw cycles and $5 \%$ sodium sulfate solution occurred in the first 100 freeze-thaw cycles. The result was consistent with $\mathrm{Li}$ et al.'s finding [12]. Besides, the decline rate of relative dynamic elastic modulus increased with increasing content of fly ash, resulting from high FA content which reduced the content of cement and decreased the basic excitant of $\mathrm{Ca}(\mathrm{OH})_{2}$ in which fly ash hydration depends [29] and accelerated the effect of the coupling action of freeze-thaw cycle and sulfate attack on the deterioration of concrete [28].

For the same content of fly ash (10\%), the RDEM continuously increased with the accumulation of concentration of salt solution before 100 freeze-thaw cycles and then decreased rapidly (Figure 4(b)). This is not consistent with Miao et al.'s research [30], who found that sulfate solution has little effect on the relative dynamic elastic modulus of concrete during the initial 300 freeze-thaw cycles. The phenomenon from the curves indicated that appropriate amount of sulfate crystals and corrosion products accumulated and precipitated in concrete specimens in 5\% concentration of salt solution, which made the concrete compact. At the later stage of freeze-thaw cycle, more salt crystallization generated in concrete resulting in an increase of heave and expansion force, while RDEM declined faster [28]. Interestingly, the RDEM of the $10 \%$ fly ash concrete specimen was similar to that of non-fly ash concrete immersed in the the same $5 \% \mathrm{Na}_{2} \mathrm{SO}_{4}$ solution, which indicates that they have comparatively close freeze-thaw resistance.

\subsection{Compressive Strength}

3.4.1. Failure Morphological Characteristics. The failure morphology for axial compression every 50 coupling cycles is shown in Figure 5. Due to the combined action of expansion and crystallization pressure, the quantity, extension length, and depth of macrocracks on the surface of concrete increased with increasing freeze-thaw cycles until failed by compression. It can be seen from the failure morphology that the damage of $20 \%$ fly ash concrete in $5 \% \mathrm{Na}_{2} \mathrm{SO}_{4}$ solution was the most serious after 200 freeze-thaw cycles, which basically fragmented into pierces subjected to compressive force. This is because the corrosion products are prone to form at the interface between cement paste and aggregate to weak their cohesiveness $[12,15]$, which was observed by SEM (Figure 6). In the initial freeze-thaw cycles, the crack expanded from top to bottom after compression failure due to strong bonding ability. With increase of freezethaw cycles, concrete obviously expanded. When the cycles reached high frequency, more "crumbs" exfoliated from concrete after compression failure due to declining internal bonding capacity.

3.4.2. The Influence of Coupling Cycles on Compressive Strength. The compressive strength curves of specimens 


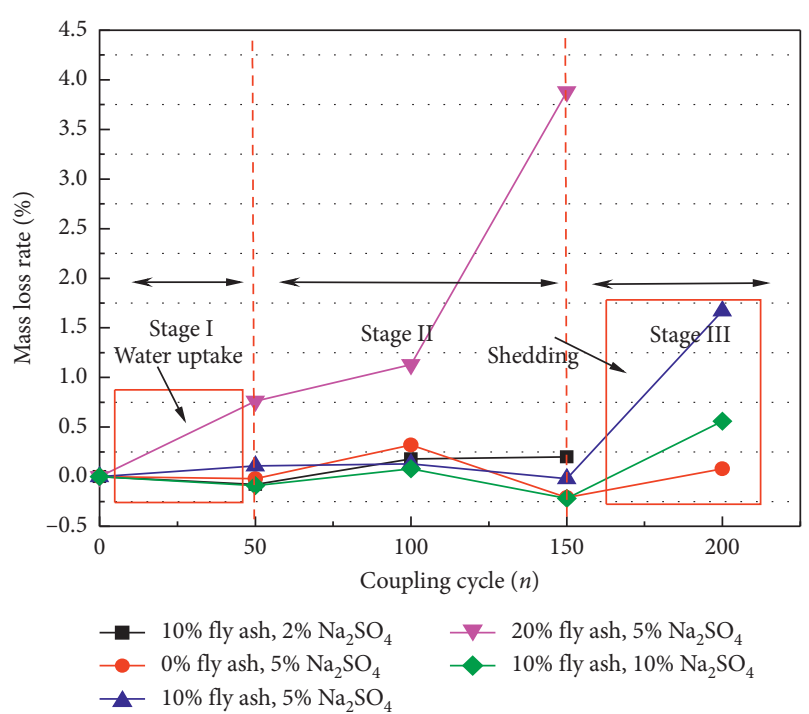

(a)

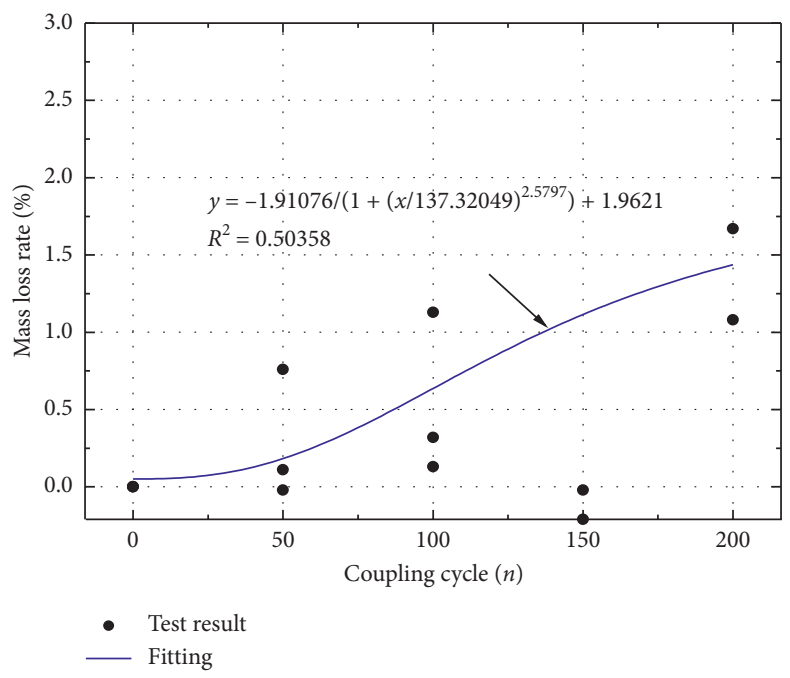

(b)

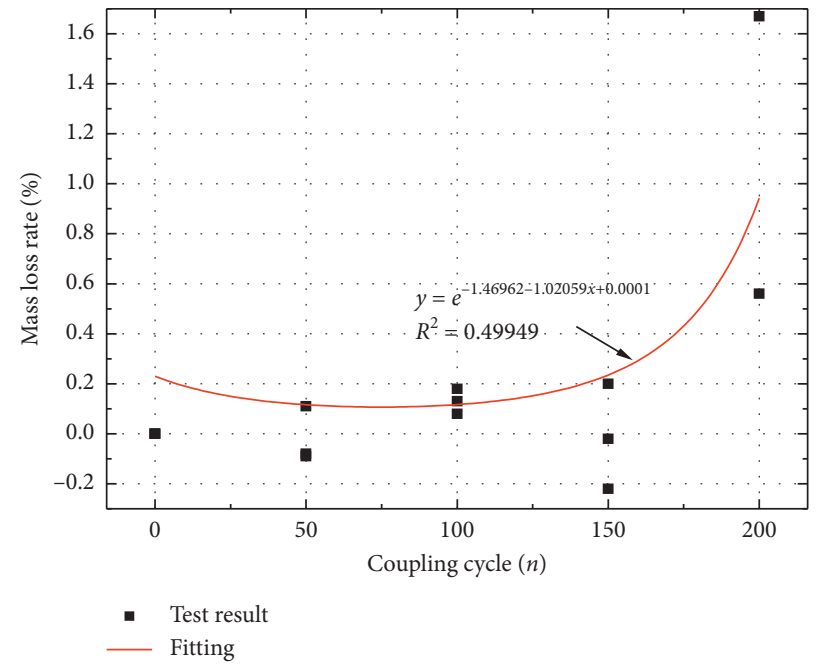

(c)

FIgURE 3: The relationship between mass loss rate and coupling cycles.

under different coupling actions of freeze-thaw and sulfate attack are plotted in Figure 7. The compressive strength decreased linearly with the increase of coupling cycles except the specimen containing $10 \%$ fly ash in $5 \% \mathrm{Na}_{2} \mathrm{SO}_{4}$ solution, which increased after 50 cycles. The main reasons were that (1) the concrete specimen in $5 \% \mathrm{Na}_{2} \mathrm{SO}_{4}$ solution was compacted because its internal capillary pore was filled with moderate amount of corrosion products and crystalline salts; besides, the pozzolanic reaction of FA improves the compactness of concrete to prevent the ingress sulfate ions and external water, which improved the compressive strength. Previous study has reported a similar finding [12]. (2) The higher the concentration of sodium sulfate solution, the more the ions enter into capillary pores of concrete, which produce corrosion products and accelerate pore solution saturation and increase the crystallization pressure. Besides, freeze-thaw cycle also provides favorable external conditions for crystallization. Expansion force of corrosion products, crystallization pressure of sulfate, and frost heave force produced by freeze-thaw were subjected on the pore jointly during the process of erosion and freeze-thaw cycles. Therefore, when the pore wall pressure exceeded the tensile strength of concrete, a large number of cracks appeared in the internal specimen, which led to rapid reduction of the compressive strength. Moreover, it cannot be ignored that compressive strength decreased faster with the accumulation of solution concentration and fly ash content in the later period of freeze-thaw cycles. This result due to high FA concrete is more sensitive to freeze-thaw effect in sulfate solution than low FA concrete [12]. High FA content reduced the content of $\mathrm{Ca}(\mathrm{OH})_{2}$ produced by hydration of cement, which is very important for stability of C-S-H. In addition, more $\mathrm{Ca}(\mathrm{OH})_{2}$ was consumed in high concentration of sodium sulfate solution. C-S-H becomes unstable in low alkalinity solution, which made concrete more prone to corrosion, so the strength decreases rapidly. 


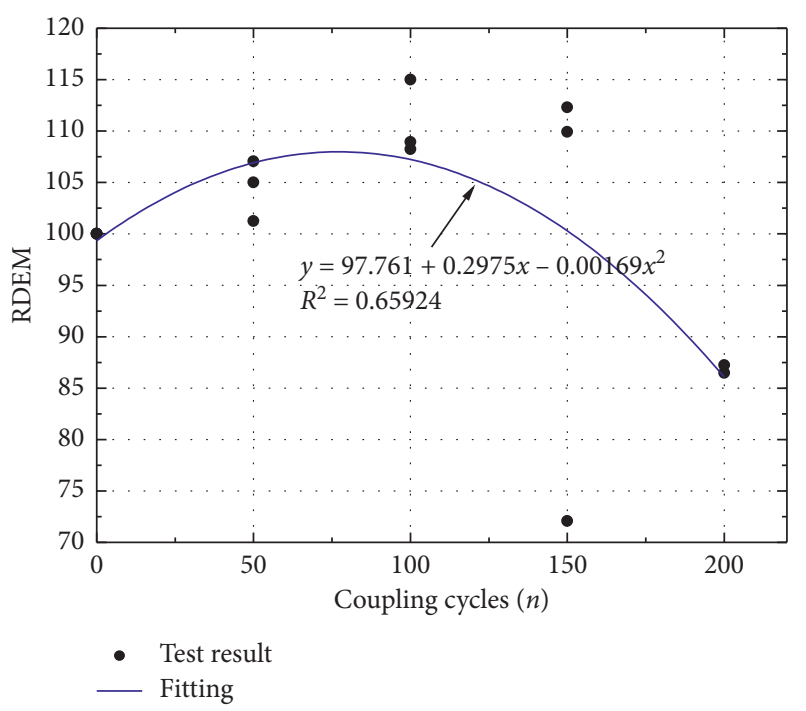

(a)

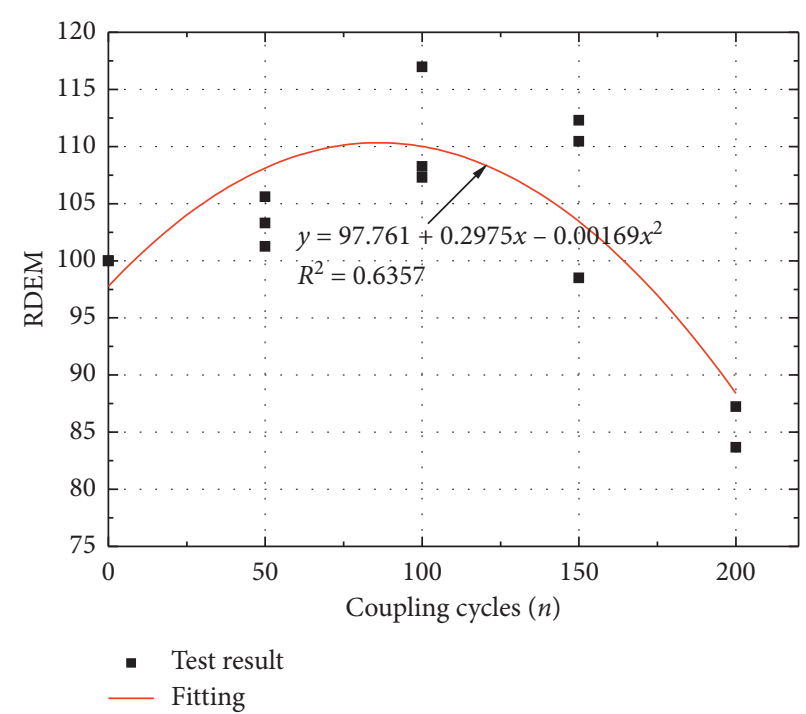

(b)

FIgURE 4: The relationship between RDEM and coupling cycles.

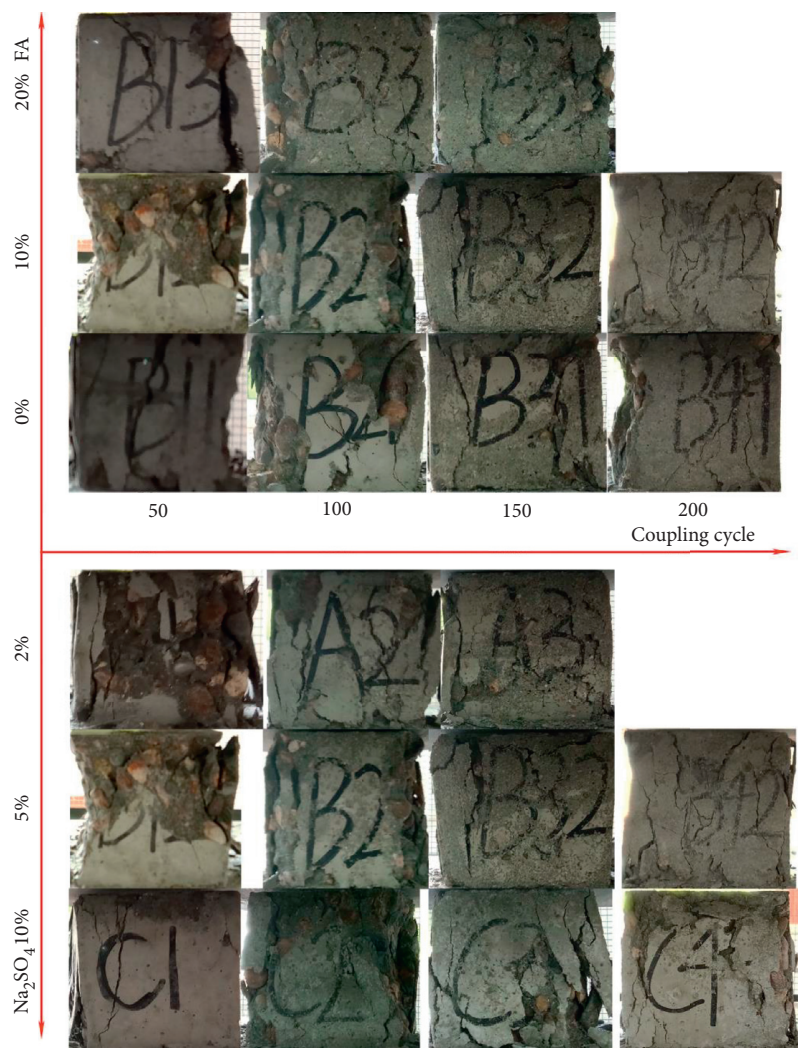

Figure 5: Compressive failure morphology of concrete with different contents of fly ash after coupling cycle.

For the same concentration of sodium sulfate solution, the compressive strength of concrete with different contents of fly ash decreased with the increase in number of freezethaw cycles, and 10\% fly ash concrete exhibited good freezethaw resistance, in which strength increased by $10.69 \%$ after 50 freeze-thaw cycles, compared with noncycles. This indicates that filling effect of corrosion products and crystalline salts enhanced strength of concrete at the initial stage of freeze-thaw. Additionally, appropriate fly ash improved interface compactness and reduced the content of $\mathrm{Ca}(\mathrm{OH})_{2}$ in this early cycle, slowing down migration rate of sulfate ions and corrosion reaction intensity to decrease the reaction products. On the contrary, high-content fly ash decreased compressive strength in later cycles.

For the same content of fly ash, the compressive strength of concrete decreased by the increase of freeze-thaw cycles at different concentrations of sodium sulfate solution. Besides, it can be seen that concrete specimens in $5 \% \mathrm{Na}_{2} \mathrm{SO}_{4}$ solution were denser than those in $2 \% \mathrm{Na}_{2} \mathrm{SO}_{4}$ solution due to more salt crystallization and corrosion products filling their original defects. Compressive strength of concrete in 5\% $\mathrm{Na}_{2} \mathrm{SO}_{4}$ solution increased by $10.68 \%$, while that in $2 \%$ $\mathrm{Na}_{2} \mathrm{SO}_{4}$ solution decreased by $11.43 \%$, compared with nonfreeze-thaw cycle. This reveals that moderate concentration of $\mathrm{Na}_{2} \mathrm{SO}_{4}$ solution inhibited freeze-thaw action in the early stage, but excessive concentration of $\mathrm{Na}_{2} \mathrm{SO}_{4}$ solution (10\%) made compressive strength of concrete to enter the decline stage ahead of time. And concrete suffers more serious damage in the salt-eroded environment after high-frequency freeze-thaw cycles.

3.5. Damage Analysis. The damage variable $D_{n}$ is defined as

$$
D_{n}=1-\frac{f_{n}}{f_{0}},
$$

where $f_{n}(\mathrm{MPa})$ is the compressive strength of concrete specimens after $n$ freeze-thaw cycles and $f_{0}(\mathrm{MPa})$ is the compressive strength of concrete specimens after 0 freezethaw cycles. And the results are plotted in Figure 8, which present a linear increasing relation between damage variable and freeze-thaw cycles. And the damage of concrete 


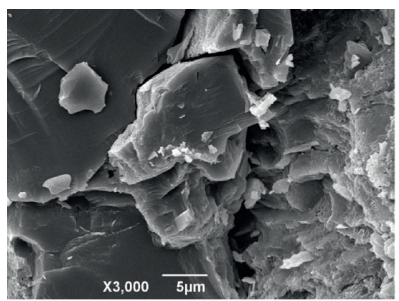

$10 \%$ FA- $2 \%$ N-100

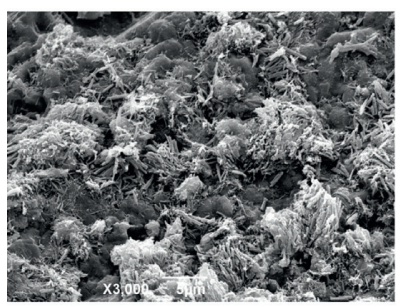

0\% FA-5\% N-150

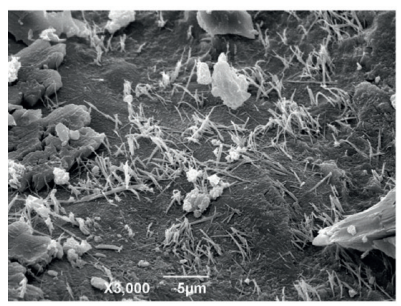

$10 \%$ FA- $5 \%$ N-150

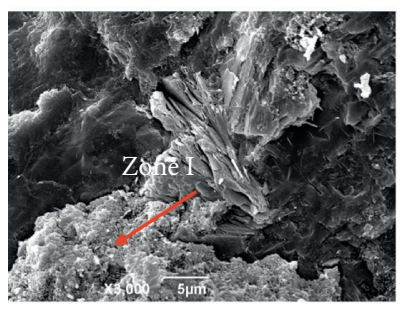

$20 \%$ FA- $5 \%$ N-100

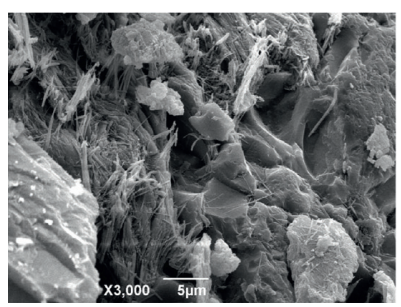

$10 \%$ FA-10\% N-150

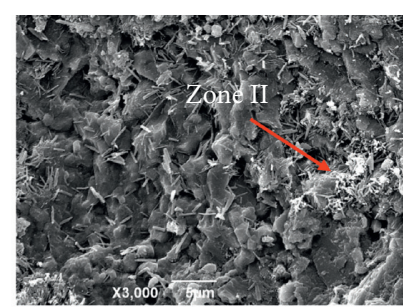

$10 \%$ FA-2\% N-150

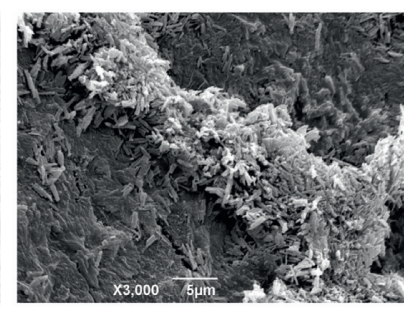

0\% FA-5\% N-200

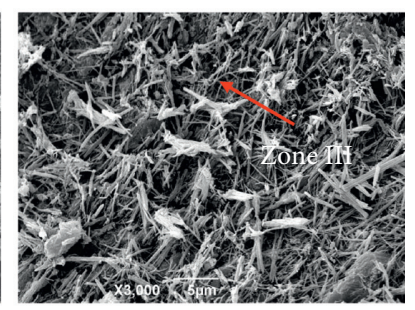

$10 \%$ FA-5\% N-200

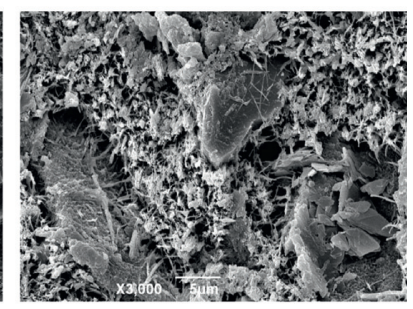

$20 \%$ FA-5\% N-150

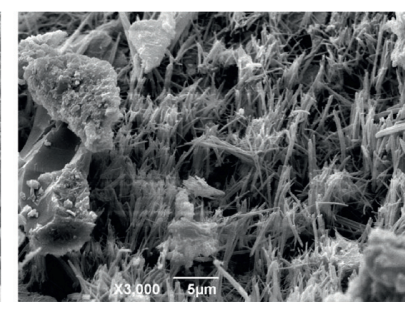

$10 \%$ FA- $10 \%$ N-200
Figure 6: SEM images of the concrete specimen (FA-fly ash and N$\mathrm{Na}_{2} \mathrm{SO}_{4}$ solution).

aggravated with the increase dosage of fly ash and $\mathrm{Na}_{2} \mathrm{SO}_{4}$ solution.

Additionally, it is obvious from Figure 8 that specimens in $5 \% \mathrm{Na}_{2} \mathrm{SO}_{4}$ solution show negative damage after 50 freeze-thaw cycles because low concentration of $\mathrm{Na}_{2} \mathrm{SO}_{4}$ solution alleviated the damage of concrete caused by a few freeze-thaw cycles. But, the damages of specimens in other two concentration solutions were higher than in 5\% $\mathrm{Na}_{2} \mathrm{SO}_{4}$ solution. The reasons may be as follows: (1) concentration of $2 \% \mathrm{Na}_{2} \mathrm{SO}_{4}$ solution was low, and no large amount of sodium sulfate crystals entered concrete to make

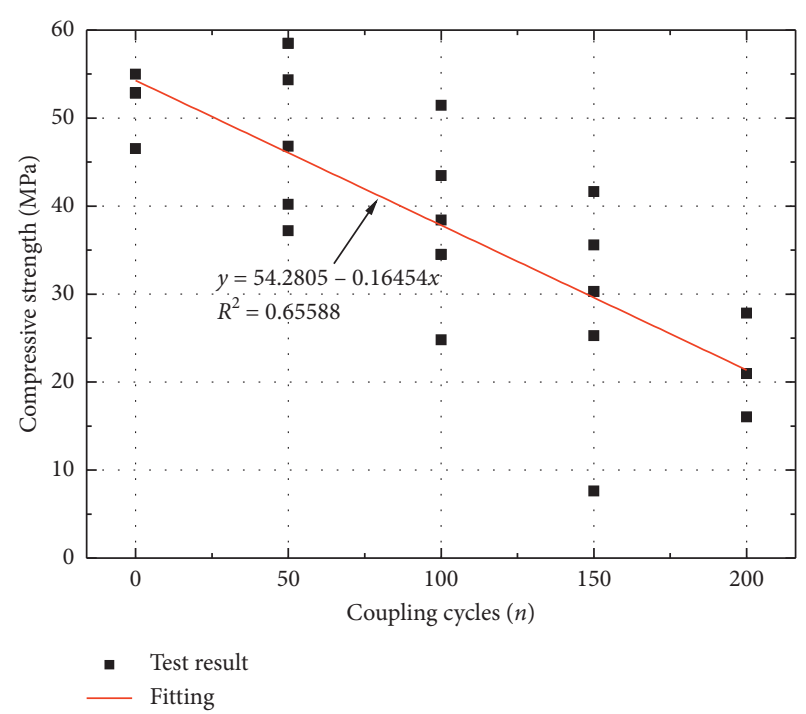

Figure 7: The relationship between compressive strength and coupling cycles.

them dense and alleviate frost heave force; (2) high concentration of $\mathrm{Na}_{2} \mathrm{SO}_{4}$ solution made specimens subject to both frost heave force and crystallization pressure. In addition, the damage deterioration rate of specimens in 5\% $\mathrm{Na}_{2} \mathrm{SO}_{4}$ solution accelerated after 150 freeze-thaw cycles, whereas that in $10 \% \mathrm{Na}_{2} \mathrm{SO}_{4}$ solution aggravated after 100 cycles. This phenomenon shows that excessive concentration of salt solution reduced inhibition of frost heave force which produced by freeze-thaw cycles and accelerated the failure of concrete specimens. Moreover, after less freeze-thaw cycles, such as 50 cycles, $D_{n}$ of the specimen containing $10 \%$ fly ash presented negative damage, which was consistent with the conclusion of the growth rule of compressive strength (i.e., the strength of fly ash concrete increases in the later period). After repeated freeze-thaw cycles, $D_{n}$ was proportional to the content of fly ash, and freeze-thaw resistance of concrete was inversely proportional to the content of fly ash.

3.6. Microappearance. Figure 6 presents SEM images of concrete specimens containing $10 \%$ and $20 \%$ fly ash content exposed to $2 \%$ and $5 \%$ sodium sulfate solutions up to 200 freeze-thaw cycles. Under the interaction of freeze-thaw and sulfate attack, microcracks occurred, and the interface between cement and aggregate cracked. With increase of sulfate attack time, cohesion and compactness of concrete mainly decreased due to the expansion of cracks, which led to the decline of macroperformance.

It is obvious from Figure 6 that a large number of erosion products, mainly "needle" ettringite and "flake" gypsum, formed after 150 freeze-thaw cycles. And the former was more obvious than the latter. No obvious corrosion products were observed in the specimens containing $10 \%$ fly ash after 100 freeze-thaw cycles in $2 \% \mathrm{Na}_{2} \mathrm{SO}_{4}$. The reasons are summarized as follows: (1) corrosion products produced in low concentration sodium sulfate solution (little $\mathrm{SO}_{4}{ }^{2-}$ ) after a few freeze-thaw cycles were less and difficult to observe; 

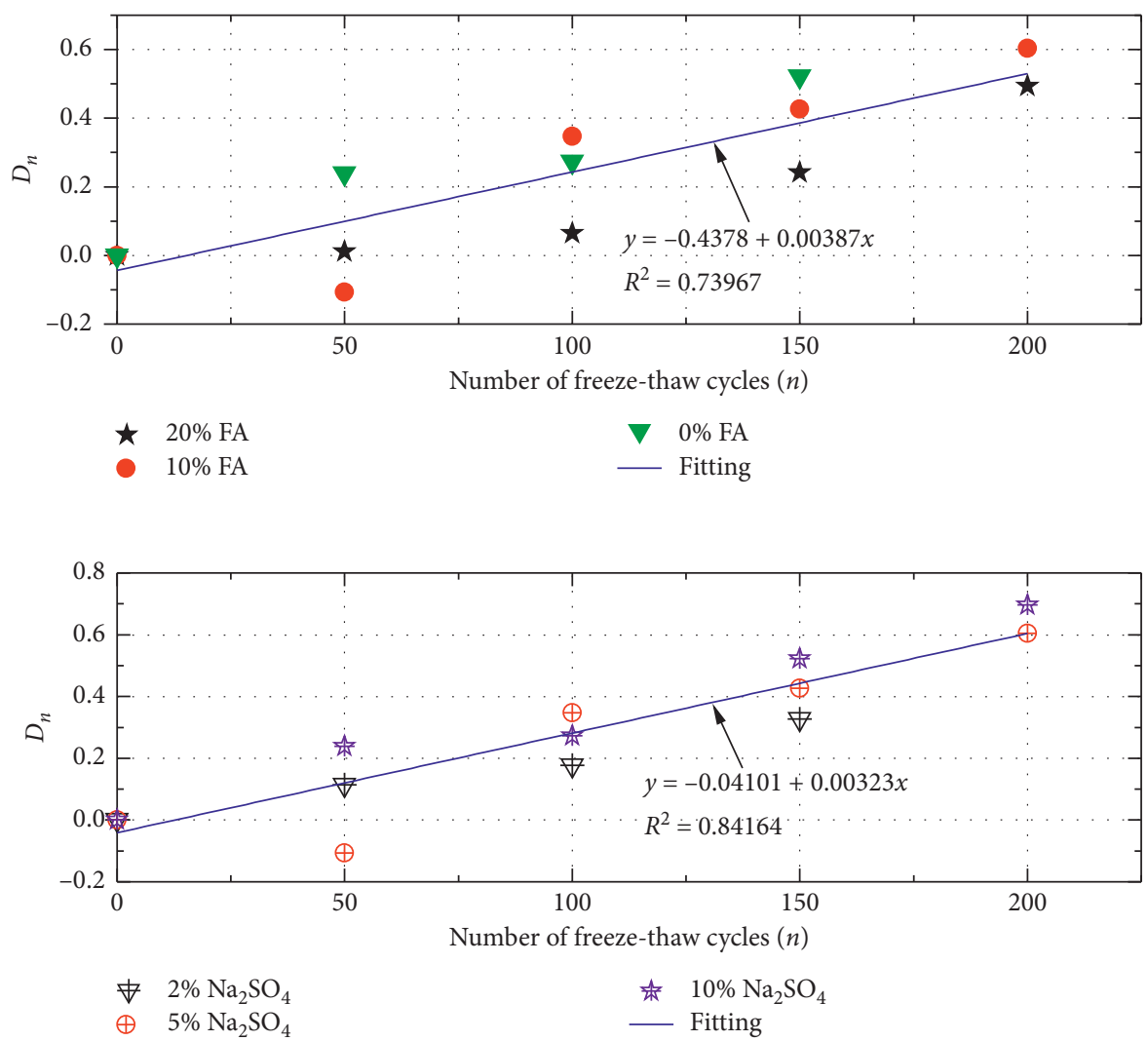

FIgURE 8: Relationship between $D_{n}$ and coupling cycles.

similar finding was reported by Niuet al. [27]. (2) freezethaw resistance of high content fly ash concrete was poor. With increasing of freeze-thaw cycles, the larger inner pores, the initiation, and propagation of microcracks led to more $\mathrm{SO}_{4}{ }^{2-}$ intruding into the interior to produce more corrosion products. Moreover, Figure 6 also shows that ettringite crystals were easily formed at the micropores, microcracks, and interface between slurry and aggregate, resulting in the decrease of cohesiveness of concrete. This was not in line with the literature [15]. Consequently, the expansion of voids and cracks caused by internal stress led to the brittleness and strength reduction of concrete.

According to SEM, the erosion products in zones I, II, and III were judged to be ettringite (AFt) by appearance (Figure 6), and correspondingly, the content of Al and $\mathrm{O}$ elements in these areas was obviously higher (Table 5), which proved this conclusion in turn.

For further qualitative analysis of products, XRD test was conducted. As shown in Figure 9, the results indicated clear diffraction peaks of ettringite and gypsum. This finding demonstrated that ettringite and gypsum were formed in concrete. And the peaks assigned to ettringite were more intense and wider in elevated concentration of $\mathrm{Na}_{2} \mathrm{SO}_{4}$ solution than those in low concentration of $\mathrm{Na}_{2} \mathrm{SO}_{4}$ solution, which indicated ettringite was the main corrosion product. Besides, the diffraction peak of gypsum appeared after 150 freeze-thaw cycles, which confirmed that the formation of ettringite was prior to that of gypsum. Similar findings $[13,15,27]$ have been reported. Moreover,
TABLE 5: Element content of corrosion products.

\begin{tabular}{|c|c|c|c|c|}
\hline & Element & Content (\%) & SD (\%) & Atom (\%) \\
\hline \multirow{7}{*}{ I } & C & 7.63 & 0.2 & 15.21 \\
\hline & $\mathrm{O}$ & 29.02 & 0.93 & 43.44 \\
\hline & $\mathrm{Na}$ & 1.43 & 0.39 & 1.49 \\
\hline & $\mathrm{Al}$ & 1.78 & 0.31 & 1.58 \\
\hline & $\mathrm{Si}$ & 6.51 & 0.33 & 5.55 \\
\hline & $S$ & 4.65 & 0.3 & 3.48 \\
\hline & $\mathrm{Ca}$ & 4.65 & 0.3 & 3.48 \\
\hline \multirow{7}{*}{ II } & $\mathrm{C}$ & 10.09 & 0.25 & 17.89 \\
\hline & $\mathrm{O}$ & 37.66 & 0.75 & 50.14 \\
\hline & $\mathrm{Na}$ & 0.89 & 0.39 & 0.83 \\
\hline & $\mathrm{Al}$ & 3.99 & 0.31 & 3.15 \\
\hline & $\mathrm{Si}$ & 9.45 & 0.34 & 7.17 \\
\hline & $S$ & 5.07 & 0.32 & 3.37 \\
\hline & $\mathrm{Ca}$ & 32.84 & 0.69 & 17.45 \\
\hline \multirow{7}{*}{ III } & $\mathrm{C}$ & 11.78 & 0.36 & 20.83 \\
\hline & $\mathrm{O}$ & 35.85 & 1.21 & 47.60 \\
\hline & $\mathrm{Na}$ & 0.54 & 0.59 & 0.50 \\
\hline & $\mathrm{Al}$ & 3.03 & 0.48 & 2.39 \\
\hline & $\mathrm{Si}$ & 9.89 & 0.51 & 7.48 \\
\hline & $\mathrm{S}$ & 4.37 & 0.49 & 2.90 \\
\hline & $\mathrm{Ca}$ & 34.54 & 1.05 & 18.41 \\
\hline
\end{tabular}

with the advance of freeze-thaw cycle, the diffraction peaks of calcium hydroxide decreased, which is in line with the actual situation that the pozzolanic reaction of FA and the increase of ettringite and gypsum gradually consumed calcium hydroxide. 


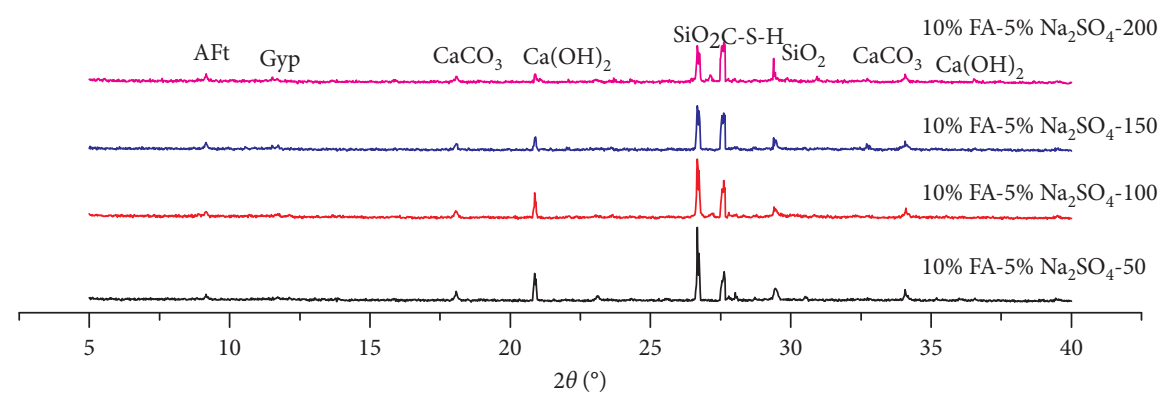

(a)

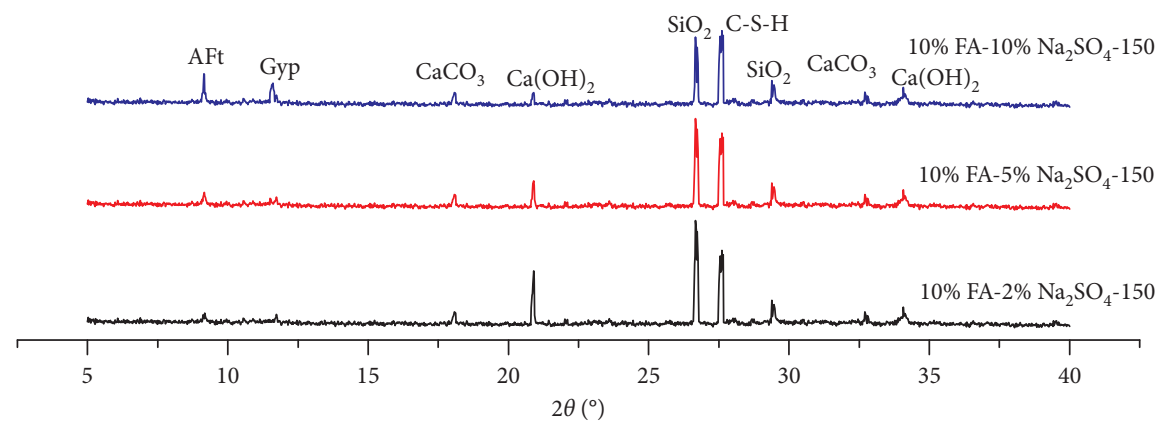

(b)

FIGURE 9: XRD analysis of concrete.

TABle 6: Pore characteristics of specimens after coupling cycle.

\begin{tabular}{lccc}
\hline Parameters & \multicolumn{2}{c}{ Coupling cycle $(n)$} & \multicolumn{1}{c}{} \\
& 50 & 150 & 200 \\
\hline Porosity $(\%)$ & 11.1496 & 0.0562 & 12.546 \\
Total pore volume $(\mathrm{ml} / \mathrm{g})$ & 0.0513 & 4.954 & 0.0588 \\
Total pore area $\left(\mathrm{m}^{2} / \mathrm{g}\right)$ & 5.035 & 45.4 & 5.805 \\
Average pore size $(\mathrm{nm})$ & 40.8 & 78.1 & 40.5 \\
Median pore diameter $\left(\right.$ volume $\left./ \mathrm{nm}^{3}\right)$ & 81 & 19 & 81.4 \\
Median pore diameter $\left(\mathrm{area} / \mathrm{nm}^{2}\right)$ & 14.5 & & 15.5 \\
\hline
\end{tabular}

3.7. Pore Characteristic. To identify the pore distribution inside the concrete, MIP analysis was conducted on the concrete specimens containing different fly ash contents exposed to combined freeze-thaw cycles and sulfate attack. The pore size can be divided into four grades: micropores $(<10 \mathrm{~nm})$, mesopores $(10-50 \mathrm{~nm})$, capillary pores $(50 \mathrm{~nm}-1 \mu \mathrm{m})$, and macropores $(>1 \mu \mathrm{m})$ [31]. The results of pore structure analysis are listed in Tables 6 and 7. According to the test results, the porosity and pore size distribution of concrete which changed under the coupling action of freezethaw cycles and sulfate attack are calculated and presented in Figures 10-12. Under the coupling action of freeze-thaw cycles and sulfate attack, the porosity increased with the increase in number of freeze-thaw cycles. In the initial stage of coupling action, the positive effect of sodium sulfate was dominant [12]. The penetration of sodium sulfate into the capillary pore reduces the freezing point of pore solution, thus reducing the damage caused by freeze-thaw cycles. Moreover, the macropores and micropores increased, while the micropores and capillary pores decreased. This difference was caused by the propagation of microcracks produced by freeze-thaw cycle, which increased the macropores (see Figure 12). However, hydration calcium silicate gel formed by the pozzolanic reaction of FA and an appropriate amount of corrosion products in 5\% sodium sulfate solution filled pores with diameters less than $0.02 \mu \mathrm{m}$ $[12,32]$. In the later stage of the coupling action, the negative effect of sodium sulfate dominated, and expansion and crystallization pressure produced by the reaction product made capillary pores turn into macropores, and the gradual penetration of cracks aggravated the deterioration of concrete. Furthermore, the porosity decreased with increase of FA content due to filling effect caused by its high fineness. And a large number of corrosion products were formed in pores exposed in high-concentration sodium sulfate solution, which gradually expanded and enlarged the pore size of mesopores and capillary pores during freeze-thaw cycles.

Mechanical strength is affected by the pore structure in a large extent, and the relationship between compressive strength, damage factor $D_{n}$, and porosity is plotted in Figure 13. It can be seen from the curve that compressive strength decreased linearly with the increasing porosity of concrete, and 
TABLE 7: Pore characteristics of concrete under different conditions after 150 coupling cycles.

\begin{tabular}{|c|c|c|c|c|c|}
\hline Parameters & $10 \%$ FA- $2 \% \mathrm{~N}$ & $0 \%$ FA- $5 \% \mathrm{~N}$ & $10 \%$ FA- $5 \% \mathrm{~N}$ & $20 \%$ FA- $5 \% \mathrm{~N}$ & $10 \%$ FA- $10 \% \mathrm{~N}$ \\
\hline Porosity (\%) & 12.1225 & 12.44 & 12.1653 & 15.9487 & 11.4801 \\
\hline Total pore volume $(\mathrm{ml} / \mathrm{g})$ & 0.0561 & 0.058 & 0.0562 & 0.0788 & 0.0524 \\
\hline Total pore area $\left(\mathrm{m}^{2} / \mathrm{g}\right)$ & 5.161 & 6.25 & 4.954 & 7.349 & 4.233 \\
\hline Average pore size $(\mathrm{nm})$ & 43.5 & 37.1 & 45.4 & 42.9 & 49.6 \\
\hline Median pore diameter (volume $/ \mathrm{nm}^{3}$ ) & 64.3 & 66.8 & 78.1 & 66.4 & 76.1 \\
\hline Median pore diameter $\left(\right.$ area $\left./ \mathrm{nm}^{2}\right)$ & 20.2 & 15.2 & 19 & 20 & 22.7 \\
\hline
\end{tabular}

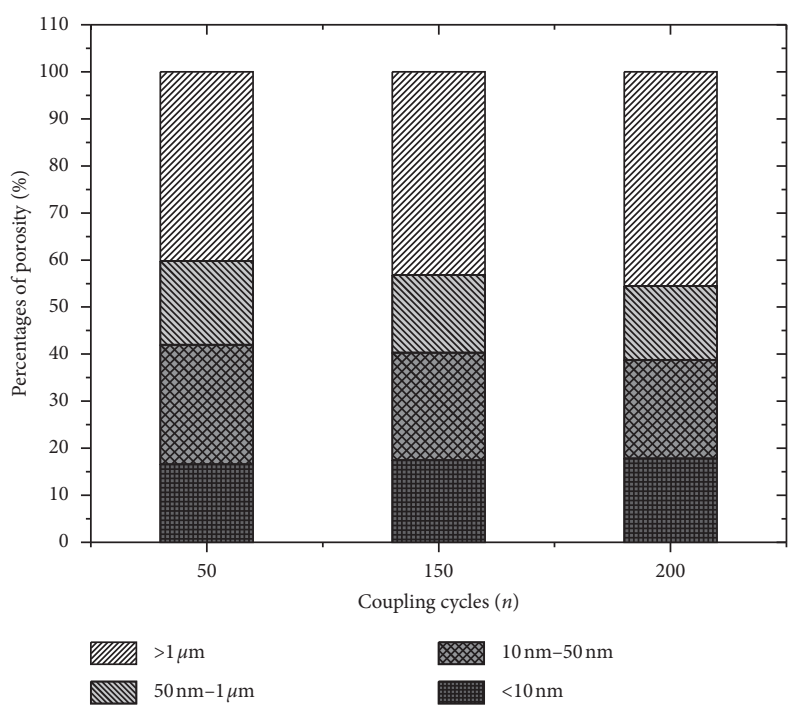

Figure 10: Relationship between pore size distribution and coupling cycles.

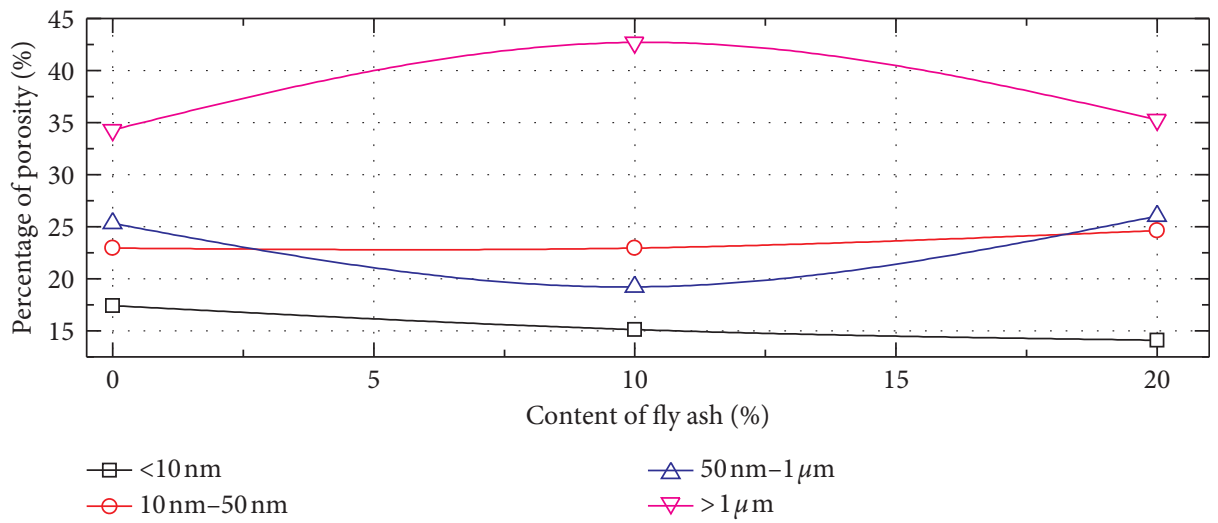

(a)

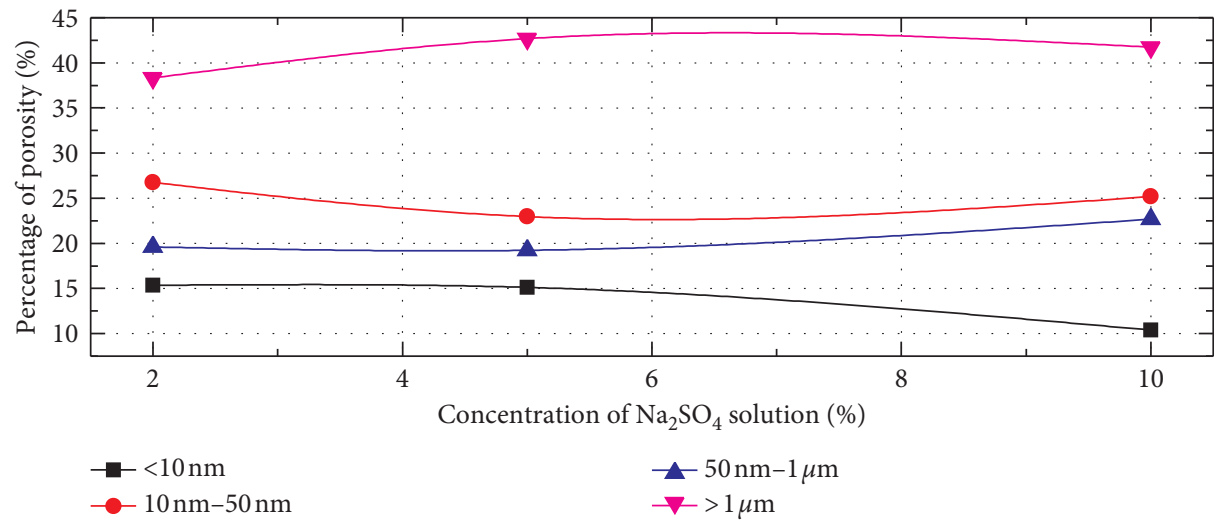

(b)

FIGURE 11: Relationship between pore size distribution and dosage of fly ash and salt solution. 


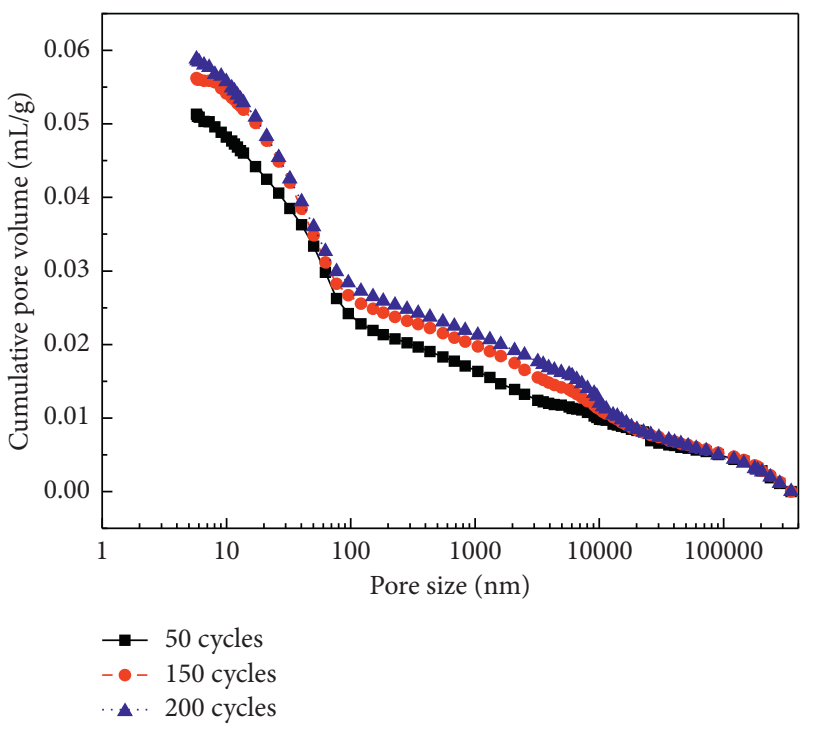

FIGURE 12: Cumulative pore volume of concrete during coupling cycle.

TABLE 8: Average formation rates of corrosion products during freeze-thaw cycles.

\begin{tabular}{|c|c|c|c|}
\hline \multirow{2}{*}{$\mathrm{Na}_{2} \mathrm{SO}_{4}(\%)$} & \multicolumn{2}{|c|}{ Average formation rates (\%) } & \multirow{2}{*}{ Fly ash (\%) } \\
\hline & $50 \sim 150(n)$ & $150 \sim 200(n)$ & \\
\hline $2 \%$ & 0.550 & - & 10 \\
\hline \multirow{3}{*}{$5 \%$} & 0.414 & 0.314 & 0 \\
\hline & 0.479 & 0.156 & 10 \\
\hline & 0.415 & - & 20 \\
\hline $10 \%$ & 0.874 & 0.380 & 10 \\
\hline
\end{tabular}

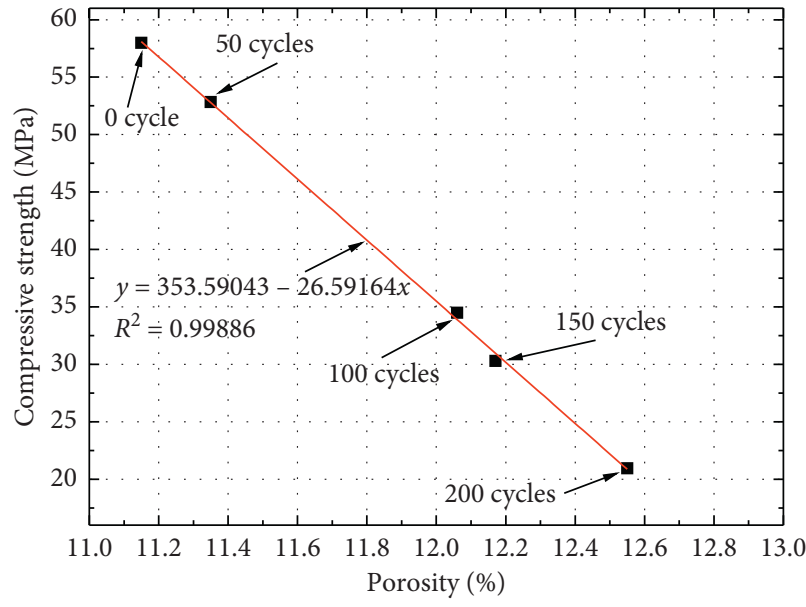

- Test result

_ Fitting curve

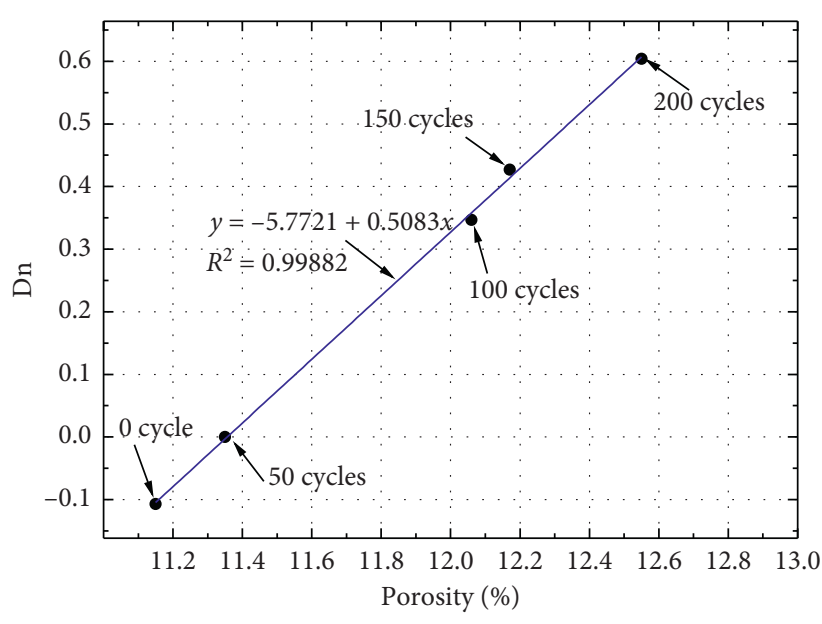

- Test result

— Fitting curve

(a)

(b)

FIGURE 13: Analysis of macroscopic properties and microstructure.

correspondingly, damage degree increases linearly with increasing porosity, indicating that the change of macromechanical properties was consistent with that of the microstructure. It presents a linear relation between $D_{n}$ and porosity during coupling cycle. It implies that, under the action of freeze-thaw cycles and sulfate attack, the damage of the pore structure caused by freeze-thaw and corrosion led to the decrease of mechanical properties under compression. Moreover, according to fitting curves, the relationship between damage factor and porosity was obtained. 


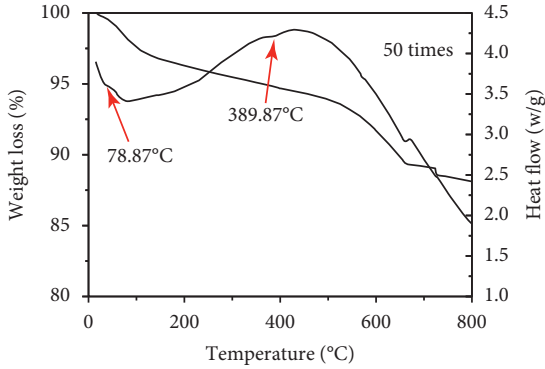

(a)

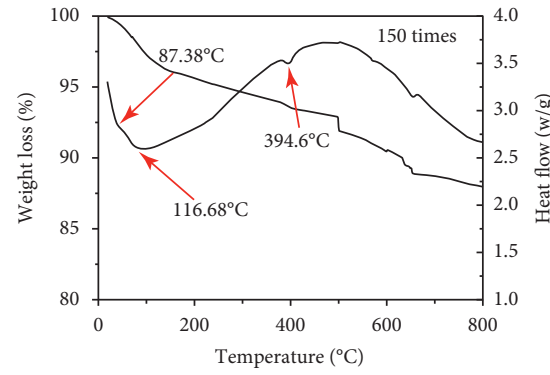

(b)

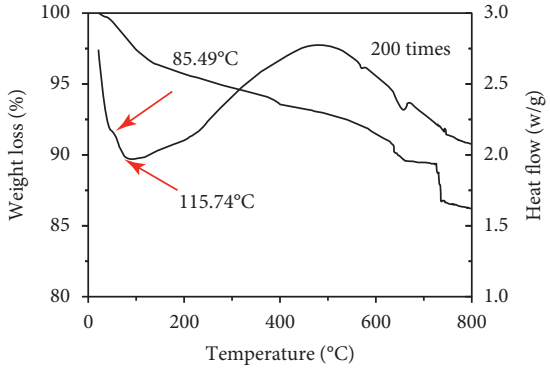

(c)

FIGURE 14: Thermal analysis curves of concrete in sodium sulfate solution after coupling cycles.
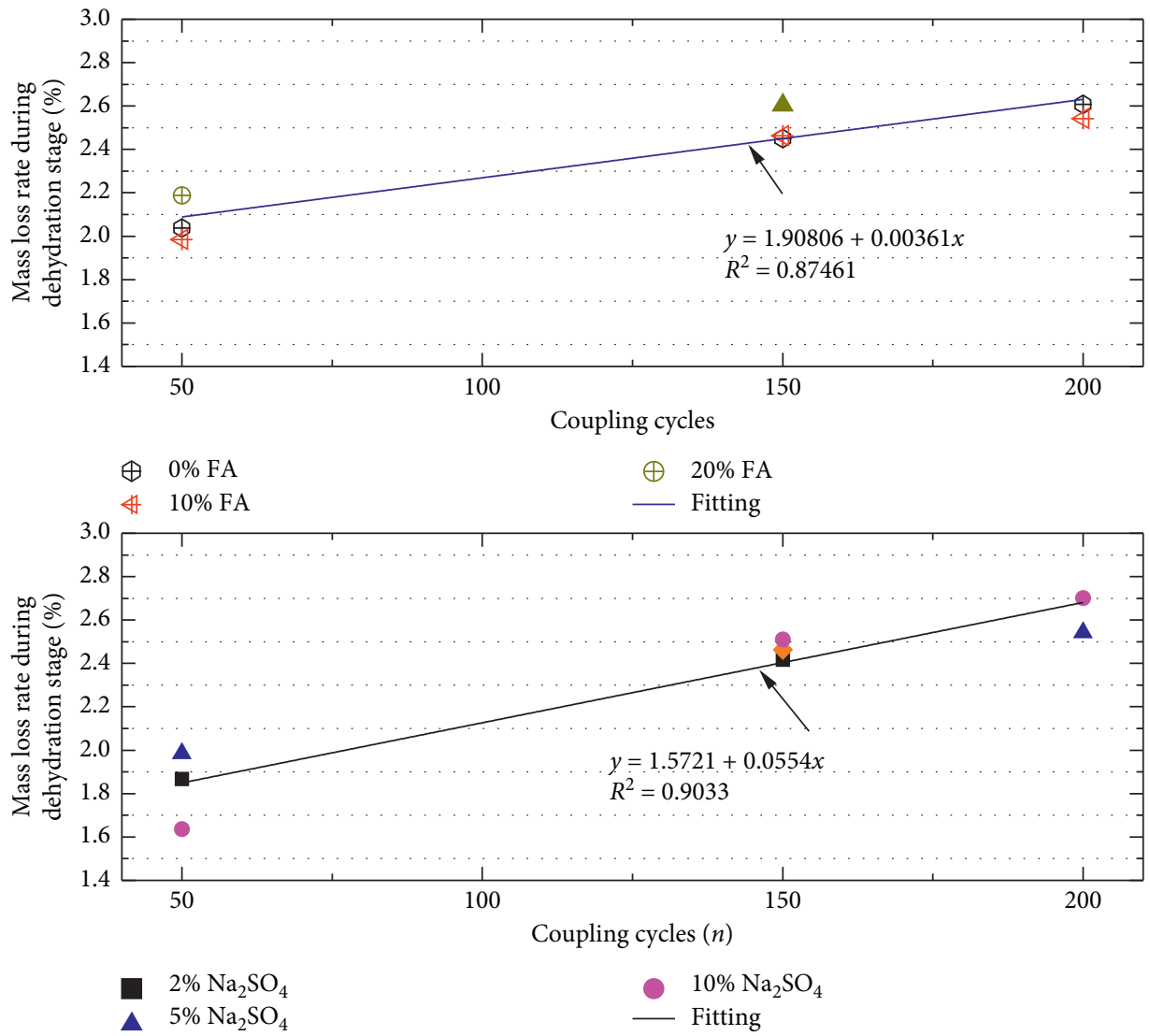

Figure 15: The relationship between mass loss rate and coupling cycle during the dehydration stage of corrosion products $\left(60^{\circ} \mathrm{C}-130^{\circ} \mathrm{C}\right)$.

$$
D_{n}=0.51 P-5.77 \text {, }
$$

where $D_{n}$ is the damage factor, $P$ is the porosity, and $n$ is the number of freeze-thaw cycles.

3.8. TG-DSC Analysis. The macroscopic properties and microstructure were also affected by corrosion products during coupling cycles; as shown in Figure 14, there are three distinct endothermic peaks on DSC curves from 0 to $500^{\circ} \mathrm{C}$, where the corresponding temperatures are $70.37^{\circ} \mathrm{C}-88.33^{\circ} \mathrm{C}$, $115.74^{\circ} \mathrm{C}-119.52^{\circ} \mathrm{C}$, and $393.65^{\circ} \mathrm{C}-402.16^{\circ} \mathrm{C}$, respectively. According to the mechanism of sulfate erosion, the corresponding substances in these three endothermic sections are ettringite $\left(3 \mathrm{CaO} \cdot \mathrm{Al}_{2} \mathrm{O}_{3} \cdot 3 \mathrm{CaSO}_{4} \cdot 32 \mathrm{H}_{2} \mathrm{O}\right)$, gypsum
$\left(\mathrm{CaSO}_{4} \cdot 2 \mathrm{H}_{2} \mathrm{O}\right)$, and calcium hydroxide $\left(\mathrm{Ca}(\mathrm{OH})_{2}\right)$. As can be seen from the curves, ettringite was formed earlier than other reaction products, gypsum was obviously formed at the later stage of freeze-thaw cycle, and the content of ettringite was higher than gypsum. The results confirmed the observation in SEM and were contrary to research by Jiang et al. [15]. We calculated the mass loss rate of concrete specimens during the dehydration stage of corrosion products according to TG curves which try to deduce the relative content of corrosion products, and the result is exhibited in Figure 15.

It demonstrated that when the content of fly ash was constant, (1) the content of corrosion products increased linearly with the increase in number of freeze-thaw cycles, 


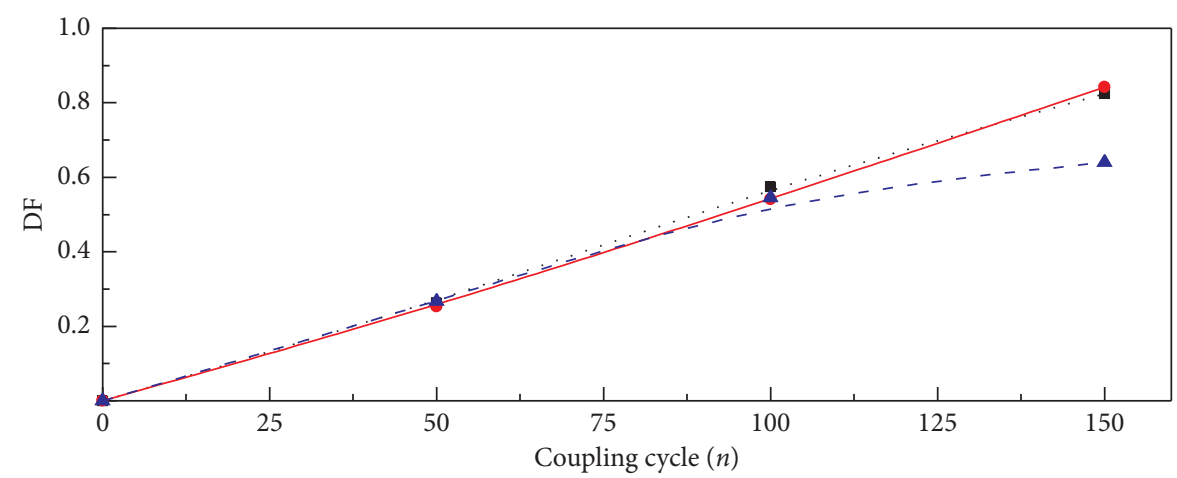

-. $0 \% \mathrm{FA}$

$\rightarrow 10 \% \mathrm{FA}$

$-\_-20 \%$ FA

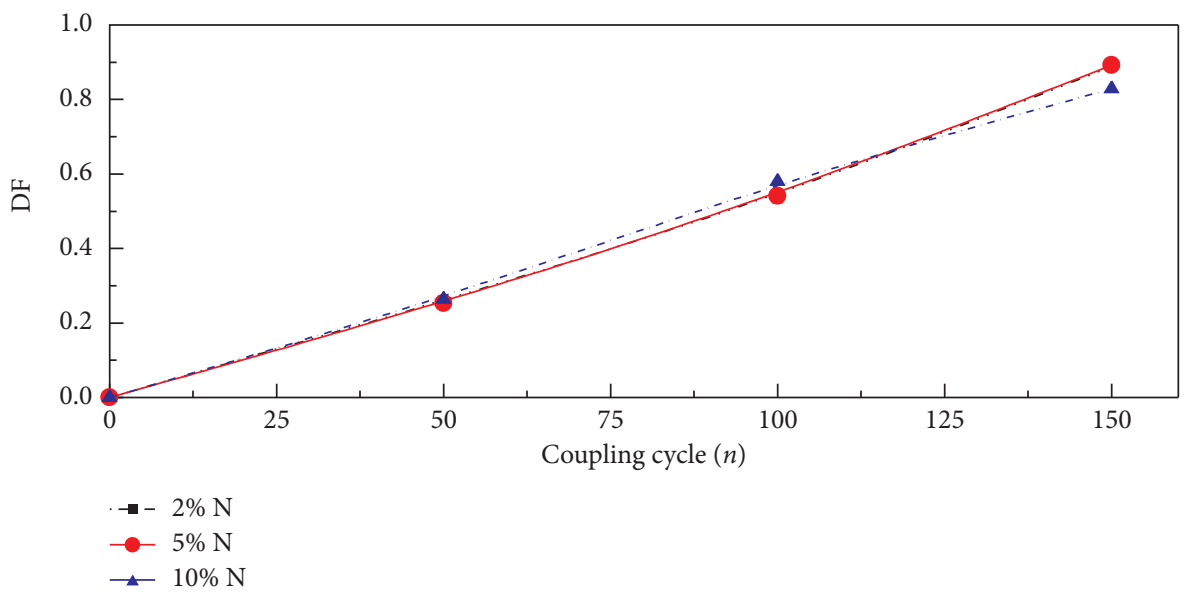

Figure 16: Relationship between DF and coupling cycles.

(2) the formation rate of corrosion products before 150 freeze-thaw cycles was higher than that after this cycle, resulting from the reduction of $\mathrm{Ca}(\mathrm{OH})_{2}$ in the later period, and (3) the content of corrosion products increased linearly with the accumulation of concentration of sodium sulfate solution at the same freeze-thaw cycles (the specimen in $10 \% \mathrm{Na}_{2} \mathrm{SO}_{4}$ solution after 50 freeze-thaw cycles was an exception. High concentration of salt solution produced more sodium sulfate crystals, blocking the inner pore of concrete, affecting the further inward migration of $\mathrm{SO}_{4}{ }^{2-}$, and thus reducing the formation of corrosion products). When the concentration of salt solution was constant, the content of corrosion products increased with the increasing content of fly ash after 150 freeze-thaw cycles. This is because when fly ash content was up to $20 \%$, the freezethaw resistance of concrete becomes weak, and microcracks and voids increased the invasion of $\mathrm{SO}_{4}{ }^{2-}$ resulting in the accumulation of corrosion products, which was consistent with the conclusion of mass loss rate in macroanalysis in this paper.

The corrosion of concrete under the coupling action of freeze-thaw cycle and sulfate attack is a process from the surface to the interior. To further investigate the internal chemical corrosion, we calculated average formation rates of corrosion products during freeze-thaw cycles, respectively, and the results are shown in Table 8 . It is clear from Table 8 that the average formation rate of corrosion products in high concentration of sodium sulfate solution was faster than that in low concentration of sodium sulfate solution. And the average formation rate of corrosion products of low FA concrete was faster than that of high FA concrete. The content and concentration of $\mathrm{Ca}(\mathrm{OH})_{2}$ and $\mathrm{SO}_{4}{ }^{2-}$ are the main factors affecting the formation rate of corrosion products. The addition of fly ash improves the compactness of concrete due to its filling effect caused by high fineness and a low alkaline calcium silicate gel prepared by the secondary reaction with calcium hydroxide of the hydration product, thus slowing down the migration of sulfate ions and corrosion reaction strength. Therefore, the sulfate resistance of concrete increased with the increase of FA content, so as to decrease the formation rates of corrosion products. However, it should be noted that high FA content also reduced the content of cement and decreased the basic excitant of $\mathrm{Ca}(\mathrm{OH})_{2}$. Calcium silicate gel is easily decomposed because of the absence of $\mathrm{OH}^{-}$ion, which makes concrete prone to corrode by high concentration of sodium sulfate solution [12]. In short, moderate fly ash content and sodium sulfate concentration made concrete dense and improved the resistance to freeze-thaw cycles. And the results implied that $10 \%$ FA concrete exposed to 


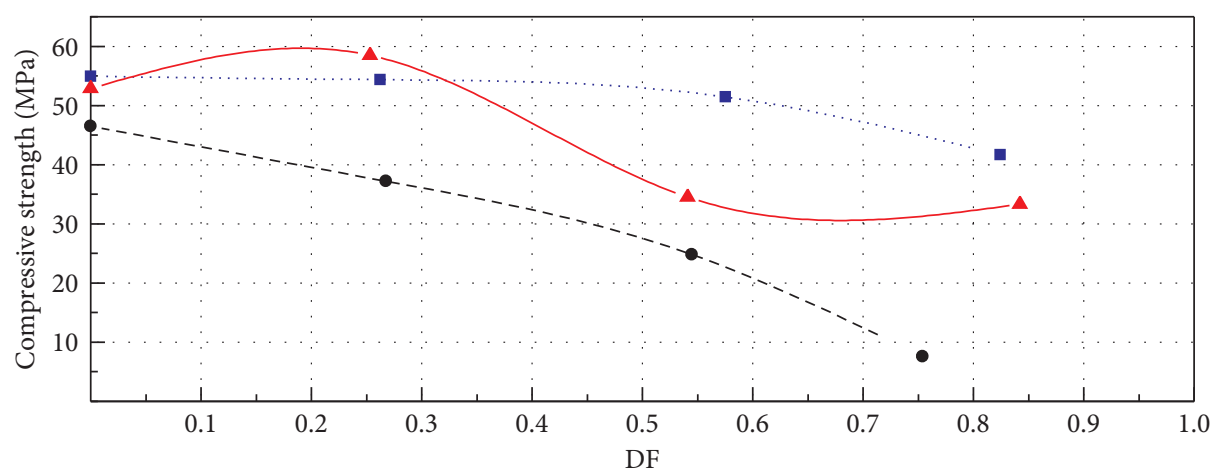

-. $0 \% \mathrm{FA}$

$-10 \% \mathrm{FA}$

- $-20 \% \mathrm{FA}$

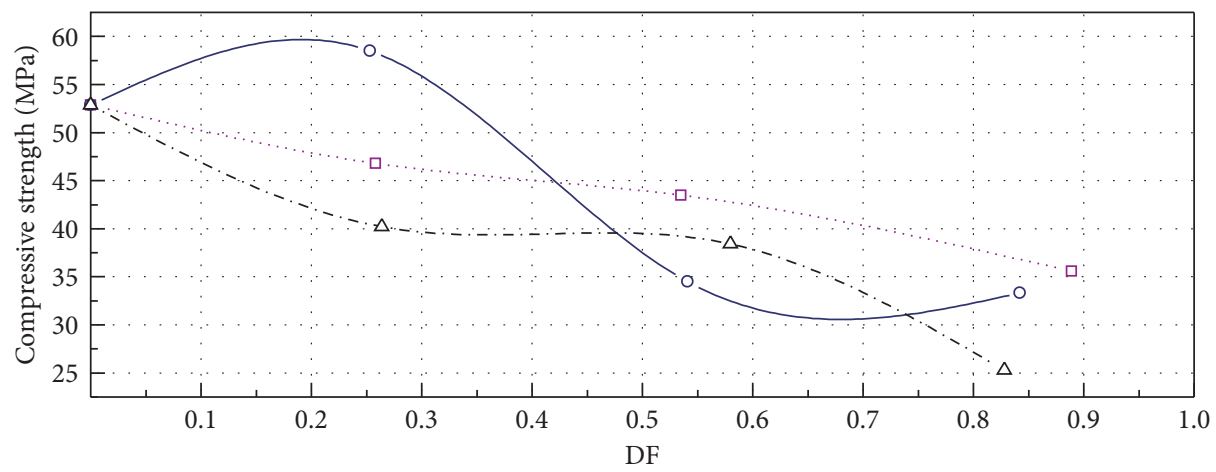

- .. $2 \% \mathrm{~N}$

- $5 \% \mathrm{~N}$

$-\triangle-10 \% \mathrm{~N}$

FIGURE 17: DF versus compressive strength before and after the coupling cycles.

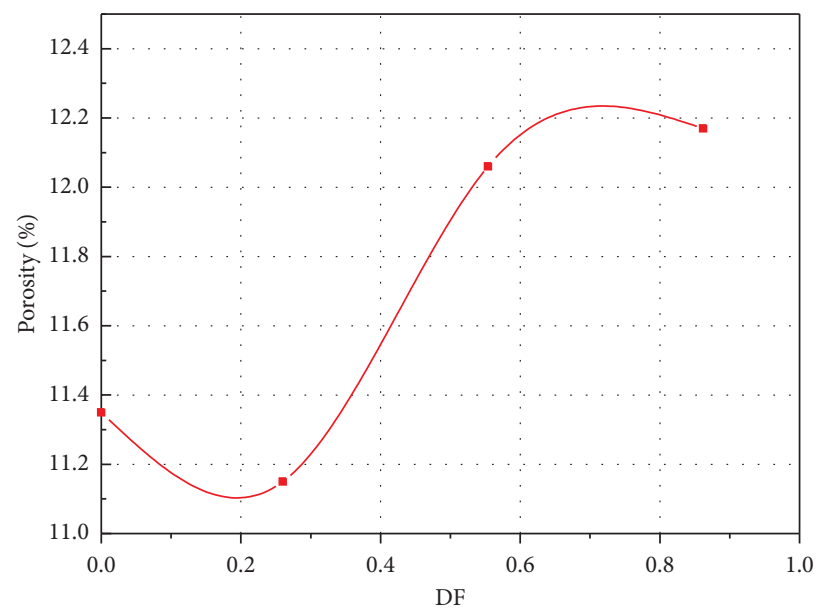

Figure 18: DF versus porosity of the typical specimen.

$5 \%$ sodium sulfate solution obtained the highest freezethaw resistance.

3.9. Freezing-Thawing Resistance of Concrete. The freezethaw resistance of concrete exposed to the combined action of freeze-thaw cycles and sulfate attack was evaluated by using damage coefficient of freeze-thaw durability. The calculation formula is as follows:

$$
\mathrm{DF}=\frac{\left(E_{n} / E_{0}\right) \times n}{200}
$$

where DF is the freeze-thaw durability damage coefficient of concrete, $E_{n}$ is dynamic elastic modulus of concrete after $n$ coupling cycles, $E_{0}$ is the initial dynamic elastic modulus, and $n$ is the number of coupling cycles. Figure $16 \mathrm{dem}-$ onstrates that DF increased with the increase of freeze-thaw cycles. This is because as the freeze-thaw cycles progress, 
damage of concrete exposed to sodium sulfate solution deteriorated, leading to the decrease in durability. In addition, the DF value of concrete containing 10\% FA in 5\% sodium sulfate solution was lower than that in other cases, indicating that it has good durability.

Figure 17 reports the relationship between DF and compressive strength of all specimens before and after coupling cycles. Variation of compressive strength is consistent with freeze-thaw durability damage coefficient of concrete. The durability damage of concrete exposed to sodium sulfate solution increased, and the strength decreased after freezethaw cycle. However, it should be noted that the compressive strength of concrete containing 10\% FA exposed to 5\% sodium sulfate solution increased first and then decreased with the increase of freeze-thaw durability damage coefficient, while it decreased continuously in the other case. Therefore, this typical batch was selected, and the relation between DF and porosity before and after freeze-thaw cycles is exhibited in Figure 18. It presents a good correspondence between porosity and DF, and it implies that, during coupling cycle, the interaction between corrosion and freeze-thaw changes porosity and pore size of concrete, and the smaller the porosity, the better the freeze-thaw resistance.

\section{Conclusions}

In this paper, the mechanical properties and microstructures of concrete under the coupling action of freeze-thaw cycles and sulfate attack were studied by multiscale experiments. Based on the obtained results, the following conclusions are drawn:

(1) During the coupling process of freeze-thaw cycle and sulfate erosion, the filling effect of fly ash and corrosion products is dominant in the rising stage of compressive strength, while the joint force is dominant in the falling stage.

(2) The corrosion products are mainly ettringite and gypsum during coupling cycle. And the content of ettringite is higher than gypsum, and its formation is also earlier than gypsum. The formation rate of corrosion products in the early stage of freeze-thaw cycles is faster than that in the later stage.

(3) Adding $10 \%$ fly ash into concrete and exposing it to $5 \%$ sodium sulfate solution can effectively improve the resistance to freeze-thaw cycle.

\section{Data Availability}

All data used in this article are available from the corresponding author by request.

\section{Conflicts of Interest}

The authors declare that they have no conflicts of interest.

\section{Acknowledgments}

The authors thank the National Natural Science Foundation of China (Grant nos. 51379015 and 51579013) and the
Fundamental Research Funds for the Central Universities, CHD (Grant no. 300102289303) for providing financial support for this project.

\section{References}

[1] Z. P. Bazant, "Physical model for steel corrosion in concrete sea structures-theory," ASCE Journal of the Structural Division, vol. 105, no. 6, pp. 1137-1153, 1979.

[2] U. Schneider, E. Nägele, and F. Dumat, "Stress corrosion initiated cracking of concrete," Cement and Concrete Research, vol. 16, no. 4, pp. 535-544, 1986.

[3] X. Shi, N. Xie, K. Fortune, and J. Gong, "Durability of steel reinforced concrete in chloride environments: an overview," Construction and Building Materials, vol. 30, pp. 125-138, 2012.

[4] A. Mardani-Aghabaglou, Ö. Andiç-Çakir, and K. Ramyar, "Freeze-thaw resistance and transport properties of highvolume fly ash roller compacted concrete designed by maximum density method," Cement and Concrete Composites, vol. 37, pp. 259-266, 2013.

[5] M. Tuyan, A. Mardani-Aghabaglou, and K. Ramyar, "Freeze-thaw resistance, mechanical and transport properties of self-consolidating concrete incorporating coarse recycled concrete aggregate," Materials \& Design, vol. 53, pp. 983-991, 2014.

[6] W. Kunther, B. Lothenbach, and J. Skibsted, "Influence of the $\mathrm{Ca} / \mathrm{Si}$ ratio of the $\mathrm{C}-\mathrm{S}-\mathrm{H}$ phase on the interaction with sulfate ions and its impact on the ettringite crystallization pressure," Cement and Concrete Research, vol. 69, pp. 37-49, 2015.

[7] J. Marchand, I. Odler, and J. P. Skalny, Sulfate Attack on Concrete, CRC Press, Boca Raton, FL, USA, 2001.

[8] F. P. Glasser, J. Marchand, and E. Samson, "Durability of concrete-degradation phenomena involving detrimental chemical reactions," Cement and Concrete Research, vol. 38, no. 2, pp. 226-246, 2008.

[9] S. Boudali, D. E. Kerdal, K. Ayed, B. Abdulsalam, and A. M. Soliman, "Performance of self-compacting concrete incorporating recycled concrete fines and aggregate exposed to sulphate attack," Construction and Building Materials, vol. 124, pp. 705-713, 2016.

[10] S.-T. Lee, R. N. Swamy, S.-S. Kim, and Y.-G. Park, "Durability of mortars made with recycled fine aggregates exposed to sulfate solutions," Journal of Materials in Civil Engineering, vol. 20, no. 1, pp. 63-70, 2008.

[11] C. J. Zega, G. S. Coelho Dos Santos, Y. A. Villagrán-Zaccardi, and A. A. Di Maio, "Performance of recycled concretes exposed to sulphate soil for 10 years," Construction and Building Materials, vol. 102, pp. 714-721, 2016.

[12] Y. Li, R. Wang, S. Li, Y. Zhao, and Y. Qin, "Resistance of recycled aggregate concrete containing low-and high-volume fly ash against the combined action of freeze-thaw cycles and sulfate attack," Construction and Building Materials, vol. 166, pp. 23-34, 2018.

[13] D. Wang, X. Zhou, Y. Meng, and Z. Chen, "Durability of concrete containing fly ash and silica fume against combined freezing-thawing and sulfate attack," Construction and Building Materials, vol. 147, pp. 398-406, 2017.

[14] M. Maes and N. De Belie, "Resistance of concrete and mortar against combined attack of chloride and sodium sulphate," Cement and Concrete Composites, vol. 53, pp. 59-72, 2014.

[15] L. Jiang, D.-T. Niu, Y.-Z. Sun, and Q.-N. Fei, "Ultrasonic testing and microscopic analysis on concrete under sulfate 
attack and cyclic environment," Journal of Central South University, vol. 21, no. 12, pp. 4723-4731, 2014.

[16] J. Wang and D. Niu, "Influence of freeze-thaw cycles and sulfate corrosion resistance on shotcrete with and without steel fiber," Construction and Building Materials, vol. 122, pp. 628-636, 2016.

[17] Y. Q. Zhang, H. F. Yu, W. Sun, and J. Y. Zhang, "Frost resistance of concrete under action of magnesium sulfate attack," Journal of Building Materials and Structures, vol. 14, no. 5, pp. 698-702, 2011.

[18] R. Putanowicz, "Implementation of pore microstructure model generator and pore space analysis tools," Procedia Engineering, vol. 108, pp. 355-362, 2015.

[19] H. Yang, X. Shen, M. Rao, X. Li, and X. Wang, "Influence of alternation of sulfate attack and freeze-thaw on microstructure of concrete," Advances in Materials Science and Engineering, vol. 2015, Article ID 859069, 7 pages, 2015.

[20] W. Tian and N. Han, "Evaluation of damage in concrete suffered freeze-thaw cycles by CT technique," Journal of Advanced Concrete Technology, vol. 14, no. 11, pp. 679-690, 2016.

[21] M. Ru, M. Changwen, L. Jiaping, and S. Wei, "Effect of $\mathrm{NaCl}$ and $\mathrm{Na} \sim 2 \mathrm{SO} \sim 4$ solution on the frost resistance of concrete and its mechanism," Journal-Chinese Ceramic Society, vol. 29, no. 6, pp. 523-529, 2001.

[22] R. Drochytka and E. Helanová, "Development of microstructure of the fly ash aerated concrete in time," Procedia Engineering, vol. 108, pp. 624-631, 2015.

[23] P. Walczak, J. Małolepszy, M. Reben, and K. Rzepa, "Mechanical properties of concrete mortar based on mixture of CRT glass cullet and fluidized fly ash," Procedia Engineering, vol. 108, pp. 453-458, 2015.

[24] H. Yazic1, "The effect of silica fume and high-volume Class C fly ash on mechanical properties, chloride penetration and freeze-thaw resistance of self-compacting concrete," Construction and Building Materials, vol. 22, no. 4, pp. 456-462, 2008.

[25] National Standard of the People's Republic of China, GB/ T50082-2009, Standard for Test Methods of Long-Term Performance and Durability of Ordinary Concrete, China Architecture and Building Press, Beijing, China, 2009, in Chinese.

[26] National Standard of the People's Republic of China, GB/ T50081-2002, Standard for Test Method of Mechanical Properties on Ordinary Concrete, China Architecture and Building Press, Beijing, China, 2003, in Chinese.

[27] D. Niu, L. Jiang, and Q. Fei, "Deterioration mechanism of sulfate attack on concrete under freeze-thaw cycles," Journal of Wuhan University of Technology(Materials Science) Editorial Department, vol. 28, no. 6, pp. 1172-1176, 2013.

[28] Y. Li, Y. Li, Z. Guan, and Q. Ding, "Elastic modulus damage model of cement mortar under salt freezing circumstance based on X-ray CT scanning," Construction and Building Materials, vol. 191, pp. 1201-1209, 2018.

[29] M. Santhanam, M. D. Cohen, and J. Olek, "Sulfate attack research-whither now?" Cement and Concrete Research, vol. 31, no. 6, pp. 845-851, 2001.

[30] C. Miao, R. Mu, Q. Tian, and W. Sun, "Effect of sulfate solution on the frost resistance of concrete with and without steel fiber reinforcement," Cement and Concrete Research, vol. 32, no. 1, pp. 31-34, 2002.

[31] P. Monteiro, Concrete: Microstructure, Properties, and Materials, McGraw-Hill Publishing, New York, NY, USA, 2006.
[32] M. Şahmaran, E. Özbay, H. E. Yücel, M. Lachemi, and V. C. Li, "Frost resistance and microstructure of engineered cementitious composites: influence of fly ash and micro poly-vinylalcohol fiber," Cement and Concrete Composites, vol. 34, no. 2, pp. 156-165, 2012. 